\title{
Polyol mediated nano size zinc oxide and nanocomposites with poly(methyl methacrylate)
}

\author{
A. Anžlovar ${ }^{*}$, K. Kogej ${ }^{2}$, Z. Crnjak Orel ${ }^{1}$, M. Žigon ${ }^{1}$ \\ ${ }^{1}$ National Institute of Chemistry, Hajdrihova 19, SI-1000, Ljubljana, Slovenia \\ ${ }^{2}$ University of Ljubljana, Faculty of Chemistry and Chemical Technology, Aškerčeva 5, Ljubljana, Slovenia
}

Received 19 October 2010; accepted in revised form 17 January 2011

\begin{abstract}
Organophilic nano $\mathrm{ZnO}$ particles have been synthesized in various diols (ethylene glycol - EG, 1,2 propane diol - PD, 1,4 butane diol - BD and tetra(ethylene glycol) - TEG) in the presence of $p$-toluenesulfonic acid, p-TsOH, as an end capping agent. The addition of $\mathrm{p}-\mathrm{TsOH}$ reduces the $\mathrm{ZnO}$ particle size and increases its crystallite size. With increasing diol main chain length the $\mathrm{ZnO}$ particle size increases (EG $(32 \mathrm{~nm})<\mathrm{PD}(33 \mathrm{~nm})<\mathrm{BD}(72 \mathrm{~nm})<\mathrm{TEG}(86 \mathrm{~nm})$ ). Using the assynthesized and unmodified $\mathrm{ZnO}$ nanocomposites with poly(methyl methacrylate), PMMA, matrix have been prepared by the in-situ bulk polymerization of methyl methacrylate, MMA. The addition of surface modifiers is avoided which is an advantage for the application since they can influence other properties of the material. ZnO particles, especially those with smaller particle sizes (EG - $32 \mathrm{~nm}, \mathrm{PD}-33 \mathrm{~nm}$ ) showed enhanced effect on the thermal stability of PMMA, ultraviolet, UV, absorption and transparency for visible light. Transparent materials with high UV absorption and with enhanced resistance to sunlight were obtained by optimizing the nanocomposite preparation procedure using $\mathrm{ZnO}$ particles of about $30 \mathrm{~nm}$ size in concentrations between 0.05 and $0.1 \mathrm{wt} \%$. The reported nanocomposite preparation procedure is compatible with the industrial process of PMMA sheet production.
\end{abstract}

Keywords: nanocomposites, ZnO nanoparticles, PMMA, UV absorption, processing technologies

\section{Introduction}

Zinc(II) oxide, $\mathrm{ZnO}$, is conventionally used as a catalyst [1] and initiator in various chemical reactions [2], gas sensor material [3, 4], UV absorber and pigment in cosmetics [5] and paints [6,7]. It is widely used in various electronic applications such as material for varistors etc. $[8,9]$. Recently it has been intensively studied as a promising material for optoelectronic devices such as light emitting diodes (LED) and flat display screens $[10,11]$. $\mathrm{ZnO}$ is considered as an interesting material for solar applications due to its unique combination of optical and semiconducting properties [12]. $\mathrm{ZnO}$ has an optical band gap in the UV region and this makes it an extremely efficient UV absorber [13]. It is also an environmentally friendly material, at least in the micrometer particle size range.

$\mathrm{ZnO}$ can be synthesized by various synthetic paths in various shapes and particle sizes [14-16]. Advanced applications require nanoparticles with narrow particle size distribution and defined particle shape. Therefore, the research activities on nanoscale $\mathrm{ZnO}$ synthesis and characterization have increased significantly in the last few years. Various synthetic approaches have been reported in the literature, including hydrothermal [17-19] and solvothermal methods [20-22], microemulsion [23], sol-gel method [24], and thermal decomposition of precursors $[25,26]$. These chemical processes are efficient methods for preparation of nanoparticles and may

\footnotetext{
*Corresponding author, e-mail: alojz.anzlovar@ki.si
}

(c) BME-PT 
be scaled up to produce large quantities of material $[27,28]$.

The polyol method is one of the solvothermal methods of $\mathrm{ZnO}$ synthesis involving the hydrolysis of $\mathrm{ZnO}$ precursors in various diols (polyols). Diols are solvents with medium polarity, dielectric constants are between 20 and 40, and they have high boiling temperatures. They can dissolve many zinc compounds and they act as solvents, reducing, as well as stabilizing agents and prevent particle growth [29-31]. Synthesis of inorganic particles in organic media is attractive because it produces particles with an organophilic surface originating from an organic medium or its degradation products. Such particles need no additional surface modification for polymer nanocomposite applications.

Poly(methyl methacrylate) is a thermoplastic material with outstanding optical properties and favorable mechanical as well as processing properties. Due to its favorable properties it can replace inorganic glass in many applications [32]. It is known that a combination of organic polymer matrices and inorganic particles offers materials with enhanced mechanical, thermal, electrical, magnetic, optical and many other specific properties. By reducing the size of filler particles to the nanometer range, their specific surface area as well as the interface area in composites is substantially increased and, consequently, their impact on composite properties is either enhanced or the same impact is achieved at lower concentrations of the filler. By combining the nano $\mathrm{ZnO}$ and PMMA matrix, transparent materials with high UV absorption can be prepared, providing that homogeneous particle distribution in the polymer matrix is achieved. For that reason the particle surface needs to be hydrophobically modified. In most cases various organic ligands are used for modification, such as: alkyl silanes, oligomeric silicones, alkyl phosphonic or fatty acids as well as various statistical and block copolymers [33-37]. By in-situ bulk polymerization of MMA in the presence of $\mathrm{ZnO}$ nanoparticles, transparent $\mathrm{ZnO} / \mathrm{PMMA}$ nanocomposites with a high concentration of $\mathrm{ZnO}$ have already been prepared [38-43].

The aim of our work was first to synthesize nano $\mathrm{ZnO}$ with organophilic surface and narrow particle size distribution by the polyol method in various diols. $p$-Toluenesulfonic acid as an end capping agent was used at high concentrations, giving $\mathrm{ZnO}$ particles with average sizes between 20 and $100 \mathrm{~nm}$ in gram quantities. Second, we tested the as-synthesized nano $\mathrm{ZnO}$ for preparation of homogeneous and transparent $\mathrm{ZnO} / \mathrm{PMMA}$ nanocomposites with high UV absorption and with improved thermal stability.

\section{Experimental section}

\subsection{Materials}

Ethylene glycol (Merck, p.a.,); 1,2 propane diol (for synthesis, Merck,Germany); 1,4 butane diol (99\%, Sigma-Aldrich, St. Louis, USA); Tetra(ethylene glycol) (99\%, Sigma-Aldrich, St. Louis, USA); Zinc (II) acetate monohydrate $\mathrm{Zn}(\mathrm{Ac})_{2}$ (99\%, ACS reagent, Sigma-Aldrich, St. Louis, USA); $p$-Toluenesulfonic acid monohydrate - p-TsOH $(98.5 \%$, ACS reagent, Sigma-Aldrich, St. Louis, USA); Methyl methacrylate (99\%, Sigma-Aldrich, St. Louis, USA); 1,1-Azobis(1-cyclohexanecarbonitrile) - AICN (98\%, Sigma-Aldrich, St. Louis, USA); ethanol (96\%, technical, Ke-Fo, Slovenia).

\subsection{Synthesis of $\mathrm{ZnO}$ nanoparticles}

Zinc(II) acetate $(1.0 \mathrm{M}), \mathrm{p}$-TsOH $(0.1 \mathrm{M})$ and deionised water $(2 \mathrm{~mol} / 1 \mathrm{~mol} \mathrm{Zn})$ were mixed with $60 \mathrm{ml}$ of EG, PD, BD or TEG and sonicated for $10 \mathrm{~min}$. The mixture was transferred into a $250 \mathrm{ml}$ glass reactor equipped with a mixer, condenser and digital thermometer. The temperature and color changes of the reaction medium were monitored over time. The temperature was raised over about $30 \mathrm{~min}$ to $170^{\circ} \mathrm{C}$ and kept constant for $30 \mathrm{~min}$ with constant stirring. Between 70 and $90^{\circ} \mathrm{C}, \mathrm{Zn}(\mathrm{Ac})_{2}$ dissolved in the glycol and the solution became transparent. After 10 minutes at $170^{\circ} \mathrm{C}$ the solution became white, and after 60 minutes of reaction a white suspension of $\mathrm{ZnO}$ was obtained. The suspension was left overnight and centrifuged at $8000 \mathrm{rpm}$ for $20 \mathrm{~min}$ to separate the particles from the supernatant. Subsequently, the $\mathrm{ZnO}$ was washed twice with ethanol followed by forced separation of $\mathrm{ZnO}$ particles in a centrifuge ( $8000 \mathrm{rpm}, 20 \mathrm{~min})$. The obtained $\mathrm{ZnO}$ powder was left to air dry. Synthesis of $\mathrm{ZnO}$ without $\mathrm{p}-\mathrm{TsOH}$ was done at $\mathrm{Zn}(\mathrm{Ac})_{2}$ concentration of $0.1 \mathrm{M}$.

\subsection{Synthesis of $\mathrm{ZnO} / \mathrm{PMMA}$ nanocomposites}

Nanocomposites of synthesized $\mathrm{ZnO}$ particles and PMMA matrix were prepared by the radical chain 
polymerization of MMA in bulk in three variations: radical polymerization between glass plates starting directly from the $\mathrm{ZnO}$ dispersion in monomer MMA (Procedure A); polymerization between glass plates starting from the previously prepared dispersion of $\mathrm{ZnO}$ in prepolymer (Procedure B); polymerization between two glass plates starting from $\mathrm{ZnO}$ prepolymer dispersion polymerized during constant sonication (Procedure C). The nanocomposite plate thickness using procedure A was $1.5 \mathrm{~mm}$, while procedures $\mathrm{B}$ and $\mathrm{C}$ gave nanocomposite plates with a thickness of $3.5 \mathrm{~mm}$. Procedures $\mathrm{B}$ and $\mathrm{C}$ were applied to reduce the shrinking of PMMA during polymerization and also to reduce the size or break up of the agglomerates of nano $\mathrm{ZnO}$ particles in the PMMA prepolymer.

Procedure A. An initiator AICN (0.0163 mol.\%) was first dissolved in MMA. Various amounts of $\mathrm{ZnO}$ powder, synthesized in diols $(0.01,0.1$ and $1.0 \mathrm{wt} \%$ ), were suspended in this solution by mixing and sonication. The solution was sonicated for $20 \mathrm{~min}$ and was then transferred into the glass plate mold and sonicated for an additional $5 \mathrm{~min}$. The glass mold was put into the water bath and MMA was polymerized for 20 hours at $75^{\circ} \mathrm{C}$. After 20 hours, the molds were taken from the bath, and PMMA sheets with a thickness of $1.5 \mathrm{~mm}$ were separated from the glass plate molds.

Procedure B. An initiator AICN (0.0163 mol.\%) was first dissolved in MMA. Various amounts of $\mathrm{ZnO}$ powder, synthesized in diols $(0.01,0.1$ and $1.0 \mathrm{wt} \%$ ), were suspended in this solution by mixing and sonication. The solution was sonicated for $20 \mathrm{~min}$ and was then transferred into the glass reactor equipped with mixer, reflux condenser and thermometer. The dispersion was heated at $80^{\circ} \mathrm{C}$ for 2 hours during constant mixing to partially polymerize the MMA. After 2 hours the prepolymer was cooled down; $20 \%$ of the new initiator dissolved in $5 \mathrm{ml}$ of MMA was added and sonicated again for $20 \mathrm{~min}$. This prepolymer was transferred to a glass mold which was put into the water bath, and MMA was polymerized for 20 hours at $75^{\circ} \mathrm{C}$. After 20 hours, the molds were taken from the bath and PMMA sheets with a thickness of $3.5 \mathrm{~mm}$ were separated from the glass plate molds.

Procedure $C$. Procedure $\mathrm{C}$ differed from procedure $\mathrm{B}$ only in that the reactor was constantly sonicated during synthesis of the prepolymer.

\subsection{Characterization methods}

The chemical composition of the intermediates and obtained particles was studied by Fourier transform infrared spectroscopy, FTIR using an FTIR spectrometer Spectrum One (Perkin Elmer, Beaconsfield, Great Britain) in the spectral range between 400 and $4000 \mathrm{~cm}^{-1}$ with a spectral resolution of $4 \mathrm{~cm}^{-1}$ in transmittance mode using the $\mathrm{KBr}$ pellets technique.

The morphology and size of the synthesized particles were studied by scanning electron microscopy - SEM. SEM micrographs of gold sputtered samples were taken on a Zeiss Supra 35 VP field emission electron microscope (Ziess, Oberkocken, Germany) at an acceleration voltage of 3.37 or $5.0 \mathrm{kV}$ using mixed in-lens and secondary electrons detectors at a ratio of $0.75 / 0.25$ and a working distance between 3-6 mm. For SEM microscopy, $\mathrm{ZnO}$ powders were placed on conductive film and sputtered with $\mathrm{Au}$. The $\mathrm{ZnO}$ particle distribution in $\mathrm{ZnO} /$ PMMA nanocomposite materials was studied by the scanning transmission electron microscopy STEM of ultramicrotomed sections of the nanocomposites. STEM micrographs were taken on a Zeiss Supra $35 \mathrm{VP}$ at an acceleration voltage of $20.0 \mathrm{kV}$ and working distance of $4.5-5 \mathrm{~mm}$ using a STEM electron detector. For STEM and HR TEM microscopy, $\mathrm{ZnO}$ particles were dispersed in an organic solvent (e.g. ethanol) by sonication and a drop of dispersion was transferred to a $\mathrm{Cu}$ grid and dried. $\mathrm{ZnO} / \mathrm{PMMA}$ nanocomposites were sectioned on the ultramicrotome Leica Ultracut (Leica, Vienna, Austria) to a thickness between 80 and $250 \mathrm{~nm}$. Particle size distribution of $\mathrm{ZnO}$ particles was obtained from STEM micrographs by image analysis using the Image Tool software.

The sizes of $\mathrm{ZnO}$ nanoparticles and their aggregates in MMA were measured by dynamic light scattering using the 3D-DLS-SLS spectrometer (LS Instruments, Fribourg, Switzerland) equipped with $20 \mathrm{mV}$ He-Ne laser (Uniphase JDL 1145 P) operating at $632.8 \mathrm{~nm}$. Scattering was measured at an angle of $90^{\circ}$. Samples in the scattering cells were immersed in a large diameter bath thermostated at $20^{\circ} \mathrm{C}$, and ten measurements of $60 \mathrm{~s}$ were recorded for each sample and averaged afterwards. In a DLS experiment the translational diffusion coefficient $D$ is determined while the hydrodynamic radius $R_{\mathrm{h}}$ is calculated from $D$ using Stokes-Einstein equation 
[44]. The viscosity of the solvent (MMA) needed for this calculation was $\eta=0.6 \mathrm{cP}$ at $20^{\circ} \mathrm{C}$.

The molecular weight distribution of the PMMA matrix was determined by size exclusion chromatography, SEC, on a modular system composed of an isocratic pump - Hewlett Packard 1100 Series (Hewlett Packard, Germany), an AM polymer GPC gel linear (1000-5 $000000 \mathrm{~g} / \mathrm{mol})$ column (AM polymer, USA), and a precolumn (AM polymer GPC gel, linear), while a differential refractometer - Hewlett Packard Agilent 1160 series (Hewlett Packard, Germany) was used as a detector. The solvent was tetrahydrofuran (THF) with a flow rate of $1 \mathrm{ml} / \mathrm{min}$, injection volume $50 \mu \mathrm{l}$ and a detector temperature $25^{\circ} \mathrm{C}$. PMMA standards were used for calibration. PMMA specimens were dissolved in THF (conc. $=2 \mathrm{mg} / \mathrm{ml}$ ) and filtered using Millipore - Millex PTFE LCR filters (Millipore, USA) with a pore diameter of $0.45 \mu \mathrm{m}$.

Crystalline fractions of the synthesized powders were characterized by wide angle X-ray diffraction (XRD) on an XPert Pro diffractometer (PANalytical, Netherlands) with a $\mathrm{Cu}$ anode as the $\mathrm{X}$-ray source. X-ray diffractograms were measured at $25^{\circ} \mathrm{C}$ in the $2 \Theta$ range from 2 to $90^{\circ}$ with a step of $0.04^{\circ}$ and step time of $1 \mathrm{~s}$. Crystallite sizes were calculated using the Scherrer formula, and an Si wafer was used to determine the experimental broadening.

Thermal properties of $\mathrm{ZnO} / \mathrm{PMMA}$ nanocomposites were studied on a Netzsch STA 409 instrument (Netzsch, Selb, Germany). DTG curves were measured in the temperature range between $50-600^{\circ} \mathrm{C}$ with a heating rate of $1^{\circ} \mathrm{C} / \mathrm{min}$ and an air flux of $100 \mathrm{ml} / \mathrm{min}$. The sample quantity was close to $50 \mathrm{mg}$.

UV-VIS spectra of $\mathrm{ZnO} / \mathrm{PMMA}$ nanocomposites were measured on an Agilent 8453 UV-VIS spectrometer (Agilent Technologies, Waldbronn, Germany) in the spectral range between 290 and $380 \mathrm{~nm}$. $1.6 \mathrm{~mm}$ thick sheets of $\mathrm{ZnO} / \mathrm{PMMA}$ nano- composites were cut to the width of a quartz cuvette.

Resistance to sun light was measured according to the ISO 4892-12 standard by exposing the specimen to a xenon light in an Atlas Sun Test CPS ${ }^{+}$ chamber (Atlas, Altenham, Germany) for 720 hours. The color change, $\Delta E$, was measured by Datacolor CR-10 color reader (Minolta, Japan).

${ }^{13} \mathrm{C}$ nuclear magnetic resonance spectra, NMR of PMMA matrices were recorded on a Varian Unity Inova $30 \mathrm{MHz}$ spectrometer (Varian, Palo Alto, California, USA) under the following quantitative conditions: pulse $90^{\circ}$, delay $2.0 \mathrm{~s}$, acquisition time $2.0 \mathrm{~s}$, and temperature $25^{\circ} \mathrm{C}$. DMSO-d6 was added in an insert and the spectra were referenced to its resonance at $39.5 \mathrm{ppm}$.

\section{Results and discussion \\ 3.1. Synthesis of nano $\mathrm{ZnO}$}

Synthesis of $\mathrm{ZnO}$ was performed in various diols (BD, TEG, EG and PD) with the addition of $\mathrm{p}-\mathrm{TsOH}$, which, according to the literature, acts as a catalyst [14]. Yields of the reaction were between 25 and $35 \%$. Nano $\mathrm{ZnO}$ powders were characterized by SEM, STEM, XRD and FTIR. The SEM and HRTEM micrographs show $\mathrm{ZnO}$ nanoparticles, synthesized in various diols with p-TsOH (Figure 1a-d). Particles are predominantly crystallites with sizes between 30 and $100 \mathrm{~nm}$ as estimated from SEM micrographs (Table 1). By the image analysis of STEM micrographs average particle sizes were calculated and are summarized in Table 1 as average Ferret diameters. The average Ferret particle diameter of $\mathrm{ZnO}$, synthesized in various diols, decreases from $86.2 \mathrm{~nm}$ (TEG) and $71.7 \mathrm{~nm}$ (BD), to $33.3 \mathrm{~nm}$ (PD) and $32.1 \mathrm{~nm}$ (EG). When particle size is presented as a function of the diols' structure, a correlation between the chain length between two $\mathrm{OH}$ groups of the diol and the average size of the $\mathrm{ZnO}$ particles was observed. Diols with a shorter chain length produce $\mathrm{ZnO}$ with a smaller average

Table 1. Crystallite sizes and average Ferret particle diameters of $\mathrm{ZnO}$ particles synthesized in various diols as well as average Ferret particle diameters of $\mathrm{ZnO}$ in nanocomposites

\begin{tabular}{|l|c|c|c|c|}
\hline Sample designation & $\begin{array}{c}\text { Particle size - SEM } \\
{[\mathbf{n m}]}\end{array}$ & $\begin{array}{c}\text { Crystallite sizes } \\
{[\mathbf{n m}]}\end{array}$ & $\begin{array}{c}\text { Ferret diameter - ZnO } \\
{[\mathbf{n m}]}\end{array}$ & $\begin{array}{c}\text { Ferret diameter-nanocomposite } \\
{[\mathbf{n m}]}\end{array}$ \\
\hline TEG no p-TsOH & $300-400$ & 17.5 & $340.0 \pm 56$ & - \\
\hline TEG & $50-100$ & 114.2 & $86.2 \pm 27$ & $135.9 \pm 46$ \\
\hline BD & $50-150$ & 75.8 & $71.7 \pm 20$ & $122.3 \pm 41$ \\
\hline PD & $30-50$ & 38.1 & $33.3 \pm 12$ & $104.0 \pm 31$ \\
\hline EG & $20-40$ & 32.6 & $32.1 \pm 13$ & $108.4 \pm 33$ \\
\hline
\end{tabular}




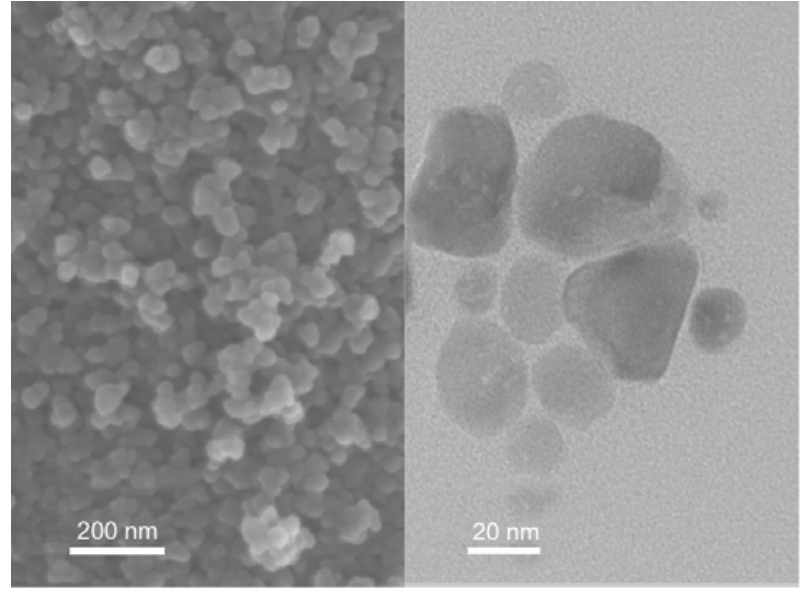

a)

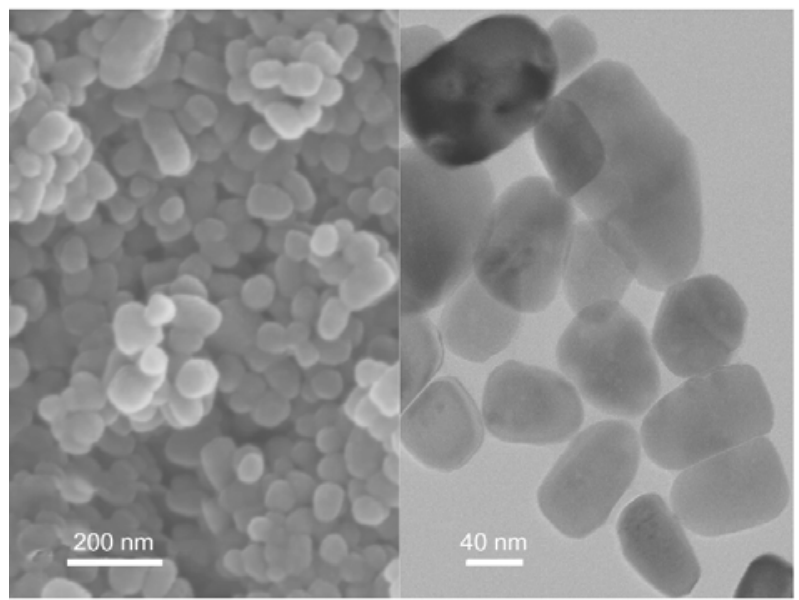

c)

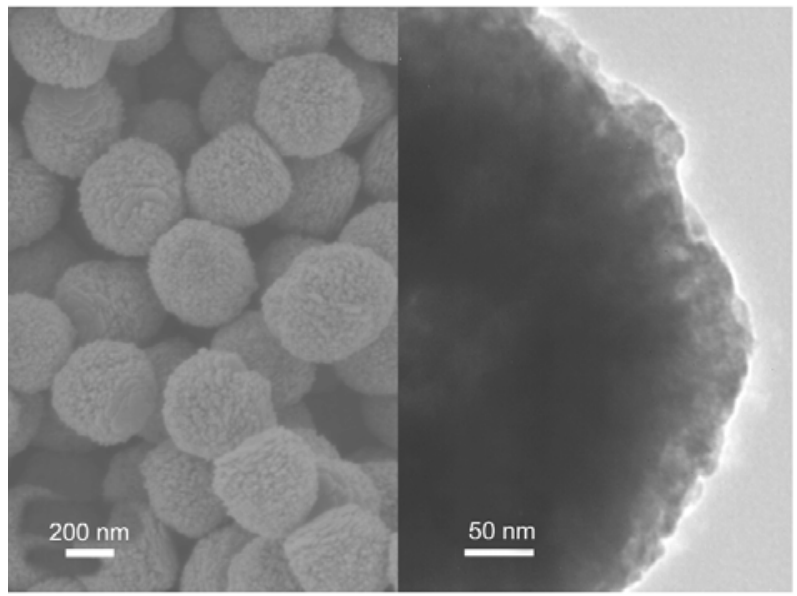

e)

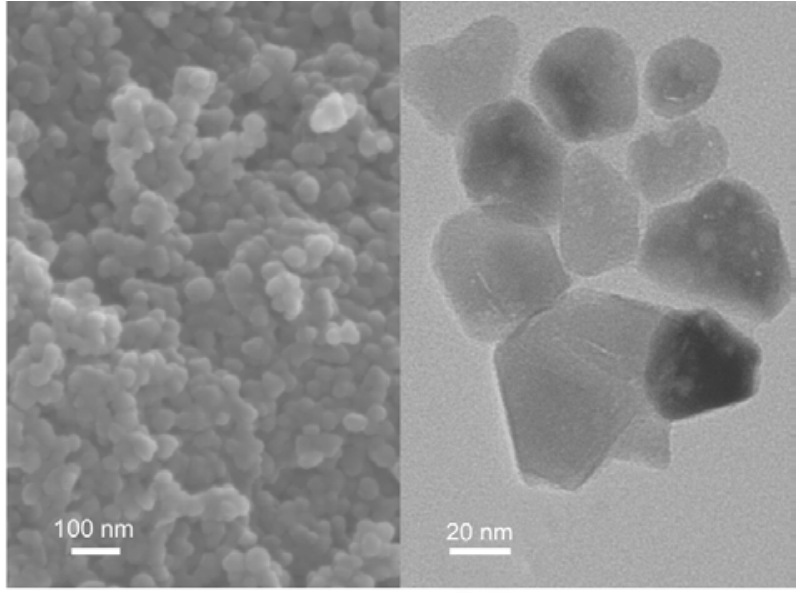

b)

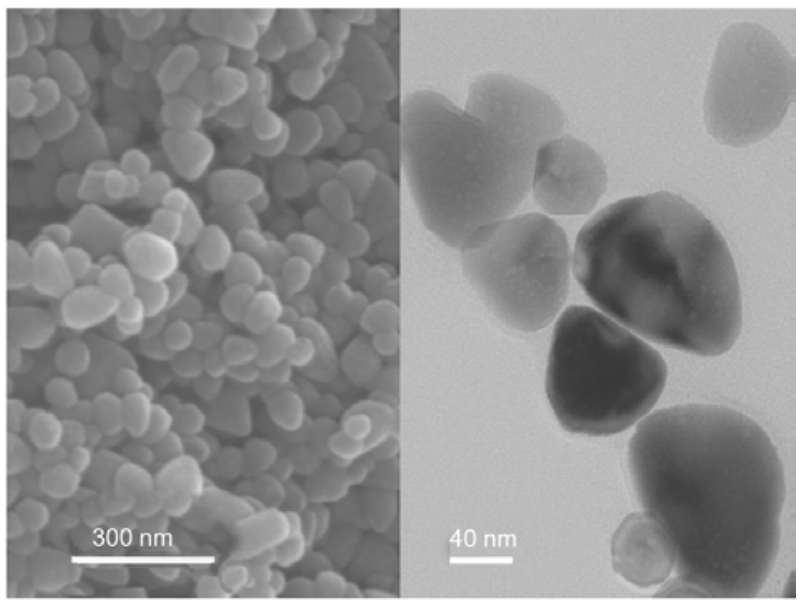

d)

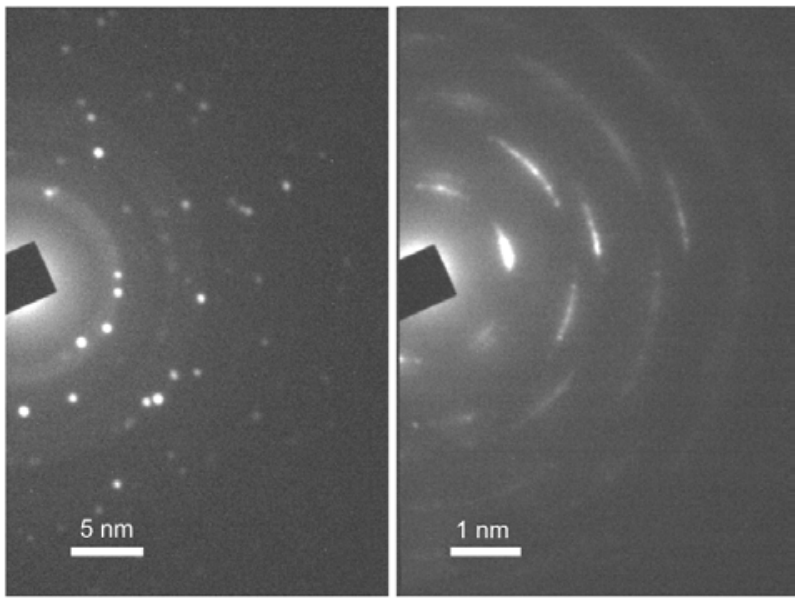

f)

g)

Figure 1. SEM and HRTEM micrographs of nano $\mathrm{ZnO}$ particles, synthesized with p-TsOH in various diols: a) EG, b) PD, c) $\mathrm{BD}, \mathrm{d}) \mathrm{TEG}, \mathrm{e}) \mathrm{TEG}$ without $\mathrm{p}-\mathrm{TsOH}, \mathrm{f}$ ) electron diffraction pattern of nano $\mathrm{ZnO}-32 \mathrm{~nm}$ (EG) and g) electron diffraction pattern of $\mathrm{ZnO}-340 \mathrm{~nm}$ (TEG without $\mathrm{p}-\mathrm{TsOH}$ )

particle size and vice versa. Similar observations were also reported by Jézéquel et al. [29]. The electron diffraction patterns of all the nano $\mathrm{ZnO}$ (Figure 1a-d) are similar and a representative pattern is shown in Figure 1f indicating that this $\mathrm{ZnO}$ is polycrystalline.
XRD diffractograms of all the $\mathrm{ZnO}$ powders synthesized in the presence of $\mathrm{p}-\mathrm{TsOH}$ show characteristic diffraction peaks of crystalline $\mathrm{ZnO}$ with hexagonal zincite structure (PDF 00-036-1451) at $2 \Theta$ values: $31.8 ; 34.5 ; 36.2 ; 47.6 ; 56.6 ; 62.9 ; 66.4$; $67.9 ; 69.1 ; 72.6 ; 76.9^{\circ}[45]$. Since all the diffrac- 


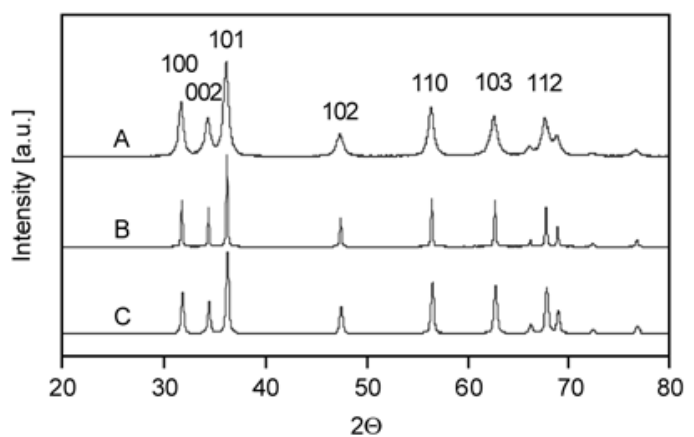

Figure 2. X-ray diffractograms of submicrometer and nano $\mathrm{ZnO}$, synthesized by the polyol procedure in:

A) TEG without $\mathrm{p}-\mathrm{TsOH}, \mathrm{B}) \mathrm{TEG}$ with $\mathrm{p}-\mathrm{TsOH}$, C) $\mathrm{PD}$ with $\mathrm{p}-\mathrm{TsOH}$

tograms are almost identical, only two samples are shown (Figure 2). Very narrow diffraction peaks indicate relatively large crystallite sizes, and crystallite sizes - calculated by the Scherrer equation [46] (Table 1), agree well with particle sizes from SEM micrographs, indicating that $\mathrm{ZnO}$ particles, synthesized in the presence of $\mathrm{p}-\mathrm{TsOH}$, are highly crystalline.

When $\mathrm{ZnO}$ was prepared in TEG without $\mathrm{p}-\mathrm{TsOH}$ by the same procedure as described above (Figure 1e), particles of submicrometer size were obtained. They have an irregular spherical shape and narrow particle size distribution. The particle size is estimated from SEM micrographs to be between 300 and $400 \mathrm{~nm}$. Synthesis of $\mathrm{ZnO}$ by the polyol method in other diols (BD, EG, PD) without $\mathrm{p}$ - $\mathrm{TsOH}$ did not give $\mathrm{ZnO}$ of a particulate shape. The XRD diffractogram of $\mathrm{ZnO}$, synthesized in TEG with no p-TsOH (Figure $2 \mathrm{~A}$ ), shows relatively wide characteristic $\mathrm{ZnO}$ diffraction maxima indicating small crystallite sizes $(17.5 \mathrm{~nm}$, Table 1$)$. Comparing the particle size and crystallite size of these particles, it is evident that they are actually agglomerates of nanocrystallites as is confirmed by SEM and HR TEM micrographs (Figure 1e). The electron diffraction pattern of this sample (Figure $1 \mathrm{~g}$ ) shows that this $\mathrm{ZnO}$ is polycrystalline. Crystallites are most probably organized in plates, which can be observed also on SEM micrograph (Figure 1e), with axes rotated for a few ${ }^{\circ}$ one to another.

Comparison of average Ferret diameters and crystallite sizes of $\mathrm{ZnO}$, synthesized in TEG with and without the addition of $\mathrm{p}-\mathrm{TsOH}$ (Table 1), leads to the conclusion that added $\mathrm{p}-\mathrm{TsOH}$ prevents the

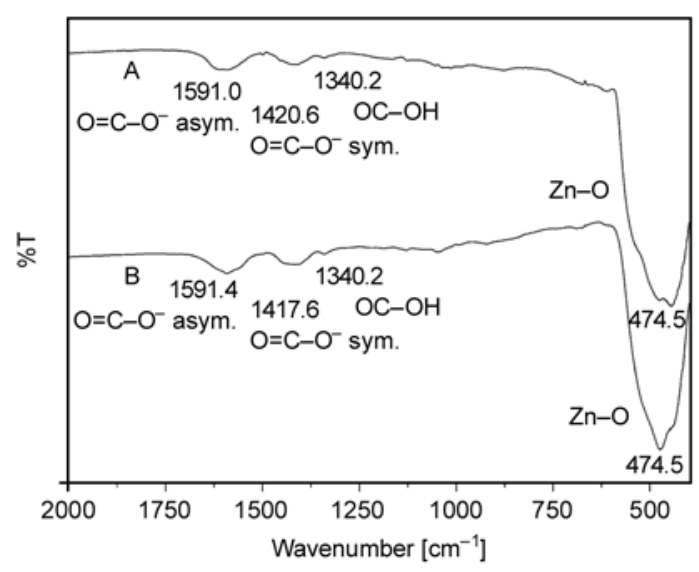

Figure 3. FTIR spectra of nano $\mathrm{ZnO}$ powders, synthesized by the polyol procedure with p-TsOH in: A) TEG, B) PD

agglomeration of nanocrystallites, thus substantially reducing the $\mathrm{ZnO}$ particle size (Figure $1 \mathrm{~d}$ and e).

FTIR spectra of all $\mathrm{ZnO}$ powders, synthesized with and without $\mathrm{p}-\mathrm{TsOH}$, show dominant characteristic $\mathrm{ZnO}$ absorption bands between 420 and $480 \mathrm{~cm}^{-1}$, which correspond to two transverse optical stretching modes of $\mathrm{ZnO}$ [47]. Since all the FTIR spectra are practically identical only two of them are shown (Figure 3). Additional absorption bands of organic species at 1590, 1415 and $1340 \mathrm{~cm}^{-1}$ were observed in all the samples. They may originate from the tetra nuclear oxo zinc acetate cluster $\left(\mathrm{Zn}_{4} \mathrm{O}\left(\mathrm{CH}_{3} \mathrm{COO}\right)_{6}\right)$ $[48,49]$ and are an indication of an organophilic particle surface. $\mathrm{Zn}_{4} \mathrm{O}\left(\mathrm{CH}_{3} \mathrm{COO}\right)_{6}$ species were identified by ${ }^{13} \mathrm{C}$ NMR spectroscopy by Berkesi et al. [50]. The ${ }^{13} \mathrm{C}$ NMR spectrum of TEG solution after $20 \mathrm{~min}$ of reaction (Figure $4 \mathrm{~b}$ ) shows a strong carbonyl peak of acetylated TEG at 171.2 and $20.4 \mathrm{ppm}$, indicating that a part of acetate groups from $\mathrm{Zn}(\mathrm{Ac})_{2}$ are involved in the esterification reaction. The resulting $\mathrm{ZnO}$ forms a complex with three molecules of $\mathrm{Zn}(\mathrm{Ac})_{2}$, generating a $\mathrm{Zn}_{4} \mathrm{O}\left(\mathrm{CH}_{3} \mathrm{COO}\right)_{6}$ cluster. In the ${ }^{13} \mathrm{C}$ NMR spectrum of the TEG solution after $20 \mathrm{~min}$ of reaction (Figure $4 \mathrm{~b}$ ) there are signals at 23.0 and $180.1 \mathrm{ppm}$, which differ from the signals of $\mathrm{Zn}(\mathrm{Ac})$ in TEG (22.4 and $178 \mathrm{ppm}-$ Figure $4 \mathrm{a})$. $\mathrm{Zn}(\mathrm{Ac})_{2}$ and $\mathrm{Zn}_{4} \mathrm{O}\left(\mathrm{CH}_{3} \mathrm{COO}\right)_{6}$ are similar molecules with respect to $\mathrm{CH}_{3}$ groups of acetate and therefore their signals in NMR spectra can not greatly differ. Nevertheless, the shift of carbonyl signal to the lower field by $2.1 \mathrm{ppm}$ is favorable to the $\mathrm{Zn}_{4} \mathrm{O}\left(\mathrm{CH}_{3} \mathrm{COO}\right)_{6}$ cluster. It is reported that the $\mathrm{Zn}_{4} \mathrm{O}\left(\mathrm{CH}_{3} \mathrm{COO}\right)_{6}$ cluster can grow to larger clusters, such as $\mathrm{Zn}_{10} \mathrm{O}_{4}\left(\mathrm{CH}_{3} \mathrm{COO}\right)_{12}$ and $\mathrm{Zn}_{34} \mathrm{O}_{16}\left(\mathrm{CH}_{3} \mathrm{COO}\right)_{24}$ 
a)
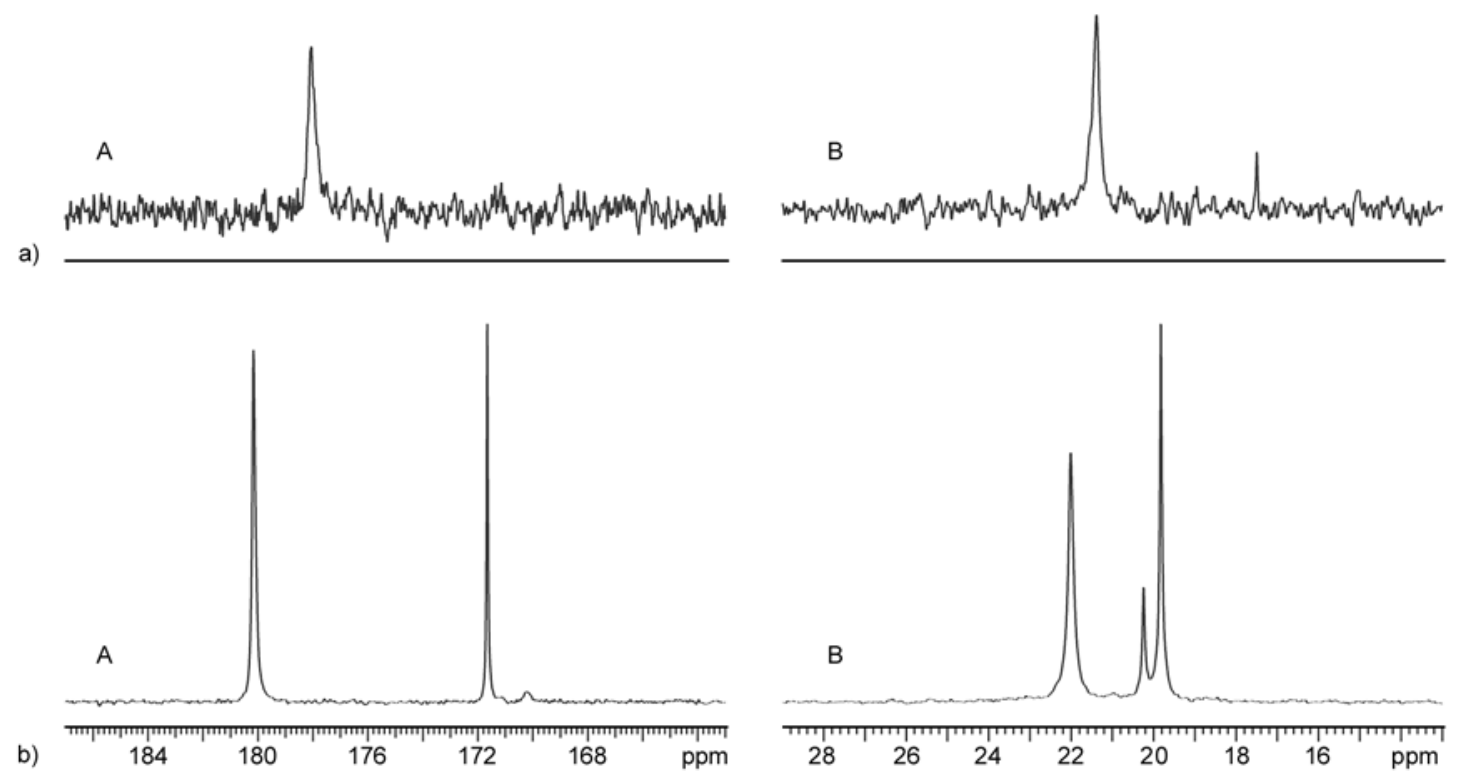

Figure 4. ${ }^{13} \mathrm{C}$ NMR spectra of: a) $\mathrm{Zn}(\mathrm{Ac})_{2}$ solution in TEG and b) reaction intermediates of $\mathrm{Zn}(\mathrm{Ac})_{2}$ hydrolysis in TEG after 20 min of reaction with p-TsOH: A) carbonyl region, B) aliphatic carbon region

[51] and so on, which are precursors for the formation of $\mathrm{ZnO}$ particles containing a $\mathrm{Zn}\left(\mathrm{CH}_{3} \mathrm{COO}\right)_{2}$ layer on the surface. Based on ${ }^{13} \mathrm{C}$ NMR results, we propose the following reaction scheme (Equations (1) and (2)) of $\mathrm{Zn}$ acetate hydrolysis in diols [52]:

$4 \mathrm{Zn}\left(\mathrm{CH}_{3} \mathrm{COO}\right)_{2}+\mathrm{H}_{2} \mathrm{O}+\mathrm{HO}-\mathrm{R}-\mathrm{HO} \leftrightarrow$ $\mathrm{Zn}_{4} \mathrm{O}\left(\mathrm{CH}_{3} \mathrm{COO}\right)_{6}+\mathrm{CH}_{3} \mathrm{COO}-\mathrm{R}-\mathrm{OOCH}_{3}+2 \mathrm{H}_{2} \mathrm{O}$

$$
\mathrm{Zn}_{4} \mathrm{O}\left(\mathrm{CH}_{3} \mathrm{COO}\right)_{6} \rightarrow 3 \mathrm{Zn}\left(\mathrm{CH}_{3} \mathrm{COO}\right)_{2}+\mathrm{ZnO}
$$

\subsection{Synthesis of nanocomposites}

Nanocomposites of unmodified as-synthesized $\mathrm{ZnO}$ particles and PMMA matrix were prepared by the free radical polymerization of MMA in bulk between two glass plates. For the preparation of homogeneous $\mathrm{ZnO} / \mathrm{PMMA}$ nanocomposites the dispersion stability of nanoparticles in the MMA monomer and the degree of their aggregation are of key impor- tance. The dispersion stability of the nano $\mathrm{ZnO}$ was studied by dynamic light scattering by monitoring the hydrodynamic radius $-R_{\mathrm{h}}$ of $\mathrm{ZnO}$ nanoparticles in the MMA monomer. Results, summarized in Table 2, show higher values of $R_{\mathrm{h}}$ at higher $\mathrm{ZnO}$ concentration as was expected, however, $R_{\mathrm{h}}$ is practically independent of time. Comparison of $R_{\mathrm{h}}$ values after 10 and 25 min shows a slight increase in size while at longer times ( $45 \mathrm{~min}$ ) $R_{\mathrm{h}}$ remains constant or even slightly decreases, meaning that nano $\mathrm{ZnO}$ dispersions in MMA are stable for at least $45 \mathrm{~min} . R_{\mathrm{h}}$ values are larger as compared to average Ferret diameters of neat $\mathrm{ZnO}$ particles (Table 1), indicating that agglomerates consist of around four to eight individual particles. $R_{\mathrm{h}}$ of $\mathrm{ZnO}$ particles, synthesized in $\mathrm{BD}$, at a concentration of $0.1 \mathrm{wt} \%$ could not be measured due to intense multiple scattering as a consequence of intense particle aggregation. The stability of $\mathrm{ZnO}$ nanoparticles in MMA can be ascribed to strong interaction between the $\mathrm{ZnO}$ sur-

Table 2. Hydrodynamic radii of $\mathrm{ZnO}$ particles in MMA dispersion in dependence on the concentration and time

\begin{tabular}{|c|c|c|c|c|}
\hline \multirow{2}{*}{ Sample designation } & \multirow{2}{*}{$\begin{array}{c}\mathrm{ZnO} \\
{[\mathrm{wt} \%]}\end{array}$} & \multicolumn{3}{|c|}{$\mathbf{R}_{\mathbf{h}}[\mathbf{n m}]$} \\
\hline & & Time (10 min) & Time (25 min) & Time (45 min) \\
\hline $\mathrm{ZnO}$ (TEG)/PMMA & 0.01 & 138 & 153 & 139 \\
\hline $\mathrm{ZnO}$ (TEG)/PMMA & 0.1 & 138 & 188 & 171 \\
\hline $\mathrm{ZnO}(\mathrm{BD}) / \mathrm{PMMA}$ & 0.01 & 107 & 98 & 103 \\
\hline $\mathrm{ZnO}(\mathrm{BD}) / \mathrm{PMMA}$ & 0.1 & - & - & - \\
\hline $\mathrm{ZnO}(\mathrm{EG}) / \mathrm{PMMA}$ & 0.01 & 83 & 81 & 84 \\
\hline $\mathrm{ZnO}(\mathrm{EG}) / \mathrm{PMMA}$ & 0.1 & 124 & 95 & 135 \\
\hline $\mathrm{ZnO}(\mathrm{PD}) / \mathrm{PMMA}$ & 0.01 & 67 & 78 & 77 \\
\hline $\mathrm{ZnO}$ (PD)/PMMA & 0.1 & 113 & 149 & 132 \\
\hline
\end{tabular}


face and the carbonyl group of MMA [53]. Molar mass averages of PMMA were measured by SEC in dependence of the polymerization time. At 45 minutes of polymerization, molar mass averages of PMMA reach values above $100000 \mathrm{~g} / \mathrm{mol}$ and due to the high viscosity of the medium, $\mathrm{ZnO}$ particles remain trapped in the polymer, and their sedimentation is prevented despite their seven times higher density compared to MMA.

Nanocomposites were first prepared by simply dispersing nano $\mathrm{ZnO}$ in MMA using sonication and by transferring the resulting dispersion into a glass mould which was put into a water bath at $75^{\circ} \mathrm{C}$ (Procedure A). STEM micrographs in Figure 5 show the distribution of $\mathrm{ZnO}$ in PMMA/ZnO nanocomposites. ZnO particles, synthesized in BD (Figure 5a) and those synthesized in TEG (Figure 5b) form larger agglomerates, while $\mathrm{ZnO}$, synthesized in PD or EG, formed small, extended agglomerates which are homogeneously distributed in the PMMA matrix (Figure $5 \mathrm{c}$ and $\mathrm{d}$ ). The lower number of par-

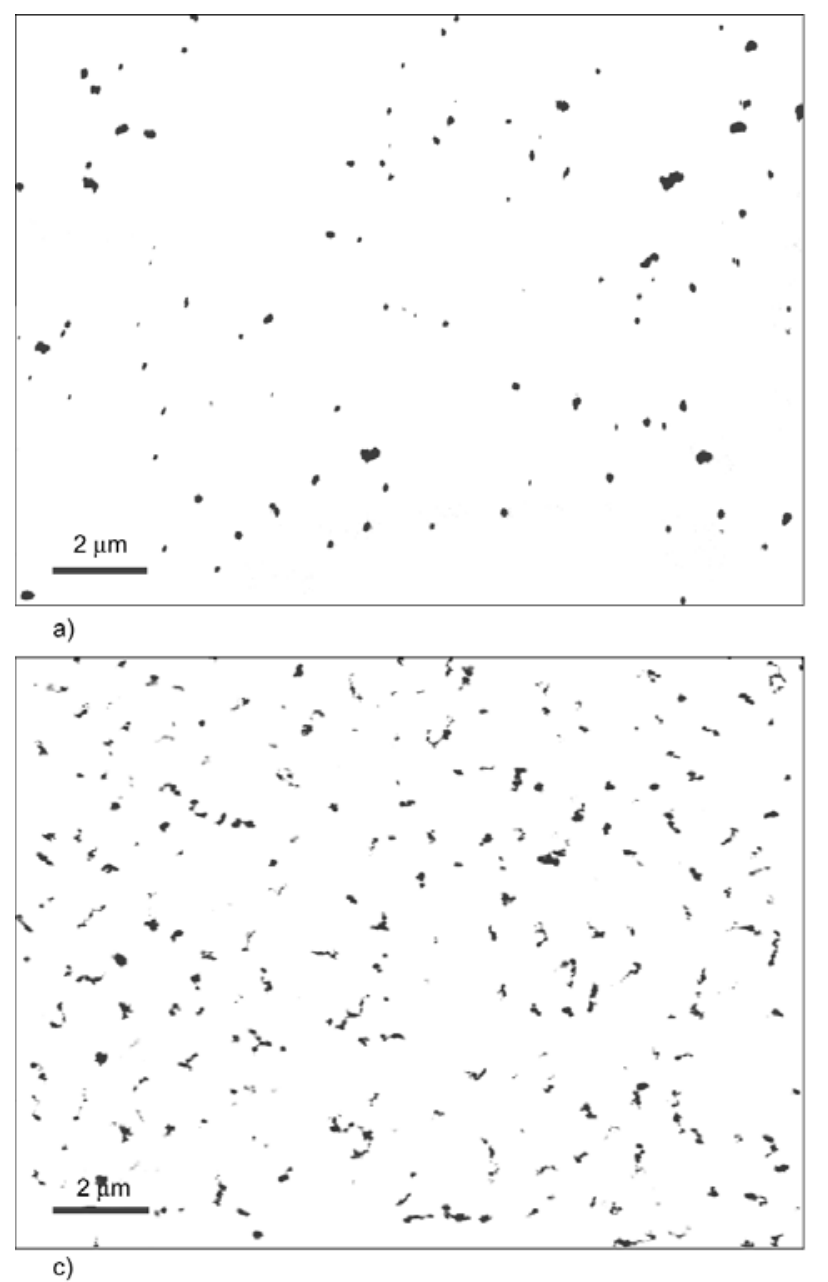

ticles or agglomerates in Figure $5 \mathrm{a}$ and $\mathrm{b}$ can be explained that larger $\mathrm{ZnO}$ particles form larger agglomerates which can partly undergo sedimentation. Ferret diameters calculated by the Image Analysis of $\mathrm{ZnO}$ particles in TEM micrographs of nanocomposites are shown in Table 1 in comparison with Ferret diameters of neat $\mathrm{ZnO}$ particles. It can be seen that average Ferret diameters of $\mathrm{ZnO}$ in nanocomposites are larger than those of neat $\mathrm{ZnO}$ particles, which means that in nanocomposites $\mathrm{ZnO}$ is slightly agglomerated (Table 1). It forms aggregates of four to eight individual $\mathrm{ZnO}$ particles. The agglomeration process is more intense for smaller particles because they provide a larger specific surface area, and thus the higher van der Waals force that causes more intense $\mathrm{ZnO}$ aggregation.

Many inorganic nanoparticles enhance the thermal stability of PMMA, when MMA is polymerized in their presence [54]. The addition of nano $\mathrm{ZnO}$ also thermally stabilizes the PMMA matrix $[37,54,55]$. The DTG curve of pure PMMA (Figure 6) shows

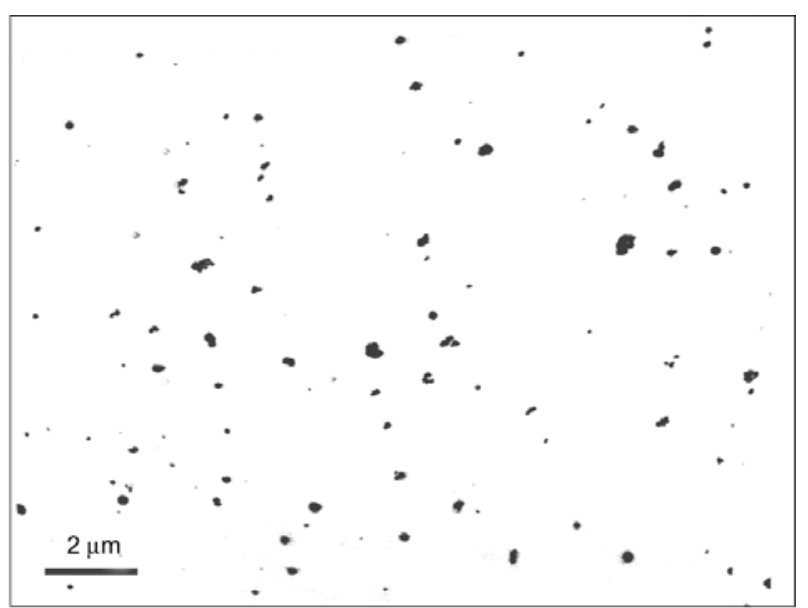

b)

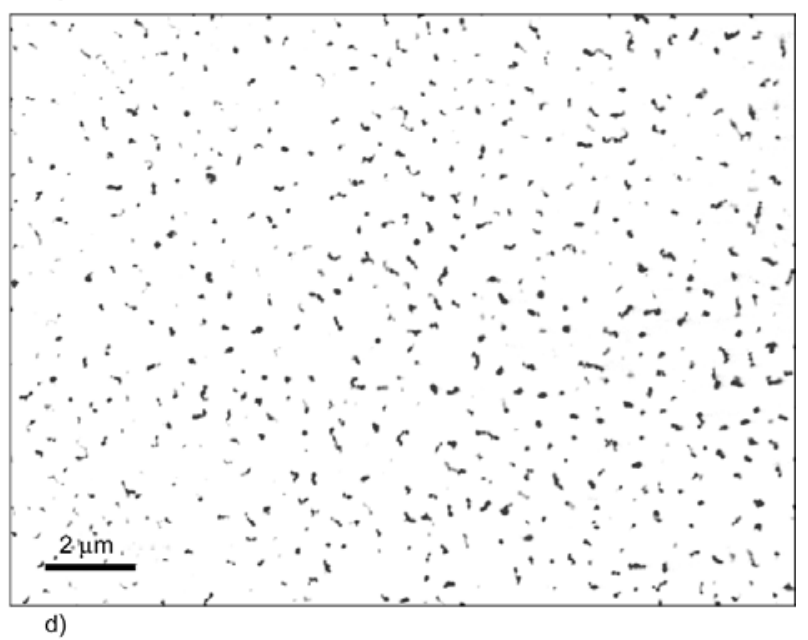

Figure 5. TEM micrographs of nanocomposites $\mathrm{PMMA} / \mathrm{ZnO}-\mathrm{ZnO}$ synthesized in various diols (nano $\mathrm{ZnO}$ concentration $=1 \mathrm{wt} \%$ ): a) BD, b) TEG, c) EG, d) PD 
three degradation peaks at 270,330 and $370^{\circ} \mathrm{C}$, which can be explained by the degradation of pure PMMA studied in nitrogen atmosphere [56]. When the temperature is increased from room temperature to $600^{\circ} \mathrm{C}$ [56], there are three steps: the first one is degradation of head to head linkages between 140 and $180^{\circ} \mathrm{C}$, the second one is scission of vinylidene double bonds between 200 and $300^{\circ} \mathrm{C}$, and the last step is random scission of the PMMA chain between 300 and $380^{\circ} \mathrm{C}$. Our measurements were done in air, and it is known that oxygen stabilizes radicals below $300^{\circ} \mathrm{C}$ (i.e. shifts degradation peaks to higher temperatures). Therefore degradation peaks in air are in the narrower temperature region, but for the assignment of degradation peaks the results obtained in $\mathrm{N}_{2}$ are still useful. DTG curves of $\mathrm{ZnO} / \mathrm{PMMA}$ nanocomposites (Figure 6a and $\mathrm{b}$ ) show much less intense peaks of vinylidene double bond degradation between 200 and $300^{\circ} \mathrm{C}$ and a stronger peak of random scission of the PMMA chain above $300^{\circ} \mathrm{C}$ compared to pure PMMA. It is evident that thermal stabilization is in correlation with the particle size: $\mathrm{ZnO}$ with particle size below $50 \mathrm{~nm}$ (Figure 6a C and D) shows more intense thermal stabilization compared to $\mathrm{ZnO}$ with particle size above $50 \mathrm{~nm}$ (Figure 6a A and $\mathrm{B}$ ) and shifts of
5 and $20 \%$ weight loss decomposition temperatures, observed in TGA curves (Table 3 ), support this conclusion. This can be attributed to the higher specific surface of $\mathrm{ZnO}$ with smaller average particle size causing stronger interaction with the PMMA matrix. The degradation peak of vinylidene double bonds reduces significantly with the increase of nano $\mathrm{ZnO}$ content (Figure 6b), indicating that their concentration may be reduced. Actually, it is reported in the literature that nano $\mathrm{ZnO}$ significantly reduces the vinylidene double bond concentration in PMMA $[54,57]$. DTG curves of samples with various concentrations of $\mathrm{ZnO}$ show that $1 \mathrm{wt} \%$ of $\mathrm{ZnO}$ is necessary to significantly change the degradation mechanism and to shift the degradation of PMMA towards higher temperatures (Figure 6b). Many authors report that relatively low filler loading (1\%) causes considerable temperature stabilization. Such low filler loadings can be explained by the large specific surface area of the $\mathrm{ZnO}$ nanofiller and by the lower concentration of vinylidene double bonds.

The most interesting property of $\mathrm{ZnO}$ from the viewpoint of its application in polymers is its extremely efficient absorption in the UV region because of its wide direct band gap of $3.37 \mathrm{eV}$ [58]. The addition of nano $\mathrm{ZnO}$ results in substantial UV
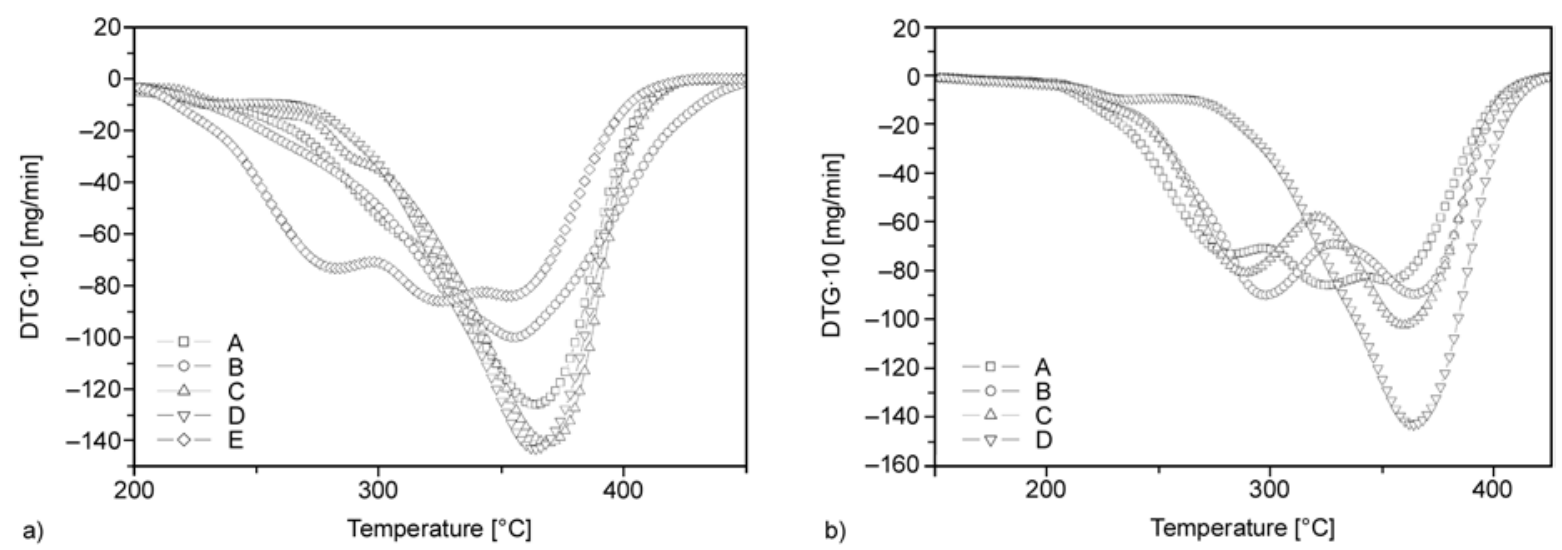

Figure 6. DTG curves of $\mathrm{ZnO} / \mathrm{PMMA}$ nanocomposites: a) as a function of $\mathrm{ZnO}$ particle size (1 wt $\% \mathrm{ZnO}) \mathrm{A}) 86 \mathrm{~nm}$, B) $72 \mathrm{~nm}$, C) $32 \mathrm{~nm}$, D) $33 \mathrm{~nm}$, E) PMMA; b) as a function of $\mathrm{ZnO}$ concentration ( $\mathrm{ZnO}$ - $33 \mathrm{~nm})$ : A) PMMA, B) $0.01 \mathrm{wt} \%$, C) $0.1 \mathrm{wt} \% \mathrm{ZnO}$, D) $1.0 \mathrm{wt} \% \mathrm{ZnO}$

Table 3. Decomposition temperatures $\left(T_{\mathrm{d}}-5 \%\right.$ weight loss and $T_{\mathrm{d}}-20 \%$ weight loss $)$ in dependence on $\mathrm{ZnO}$ particle size (concentration of nano $\mathrm{ZnO}=1 \mathrm{wt} \%$ )

\begin{tabular}{|l|c|c|c|}
\hline Sample designation & $\begin{array}{c}\text { Particle size } \\
{[\mathbf{n m}]}\end{array}$ & $\begin{array}{c}\mathbf{T}_{\mathbf{d}}-\mathbf{5 \%} \text { weight loss } \\
{\left[{ }^{\circ} \mathbf{C}\right]}\end{array}$ & $\begin{array}{c}\mathbf{T}_{\mathbf{d}}-\mathbf{2 0} \% \text { weight loss } \\
{\left[{ }^{\circ} \mathbf{C}\right]}\end{array}$ \\
\hline PMMA & - & 243 & 276 \\
\hline ZnO (TEG)/PMMA & 86 & 246 & 284 \\
\hline ZnO (BD)/PMMA & 72 & 254 & 298 \\
\hline ZnO (EG)/PMMA & 32 & 264 & 316 \\
\hline ZnO (PD)/PMMA & 33 & 274 & 322 \\
\hline
\end{tabular}


Table 4. UV transmittance of $\mathrm{ZnO} / \mathrm{PMMA}$ nanocomposites (thickness of the plates is $1.5 \mathrm{~mm}$ - Procedure A) in dependence on $\mathrm{ZnO}$ concentration and particle size

\begin{tabular}{|c|c|c|c|c|r|r|}
\hline \multirow{2}{*}{$\begin{array}{c}\text { Particle size } \\
{[\mathbf{n m}]}\end{array}$} & $\begin{array}{c}\text { ZnO } \\
{[\mathbf{w t} \%]}\end{array}$ & \multicolumn{5}{|c|}{ Transmittance at different wavelengths in the UV region } \\
\cline { 2 - 7 } & 1.0 & $\mathbf{2 9 0} \mathbf{n m}$ & $\mathbf{3 0 0} \mathbf{n m}$ & $\mathbf{3 2 0} \mathbf{~ n m}$ & $\mathbf{3 4 0} \mathbf{n m}$ & $\mathbf{3 6 0} \mathbf{n m}$ \\
\hline \multirow{3}{*}{71.7} & 0.054 & 0.243 & 0.219 & 0.118 & 0.105 \\
\cline { 2 - 7 } & 0.1 & 0.127 & 0.098 & 0.178 & 0.033 & 0.084 \\
\hline \multirow{3}{*}{86.2} & 1.0 & 0.645 & 8.880 & 9.501 & 10.494 & 11.147 \\
\cline { 2 - 7 } & 0.1 & 0.075 & 0.103 & 0.180 & 0.135 & 0.143 \\
\cline { 2 - 7 } & 0.01 & 8.266 & 11.592 & 0.210 & 0.103 & 0.244 \\
\hline \multirow{3}{*}{33.3} & 1.0 & 0.072 & 0.152 & 0.134 & 0.043 & 0.208 \\
\cline { 2 - 7 } & 0.1 & 0.508 & 0.512 & 1.196 & 1.577 & 1.271 \\
\cline { 2 - 7 } & 0.01 & 4.484 & 6.862 & 9.745 & 10.946 & 11.708 \\
\hline \multirow{3}{*}{32.1} & 1.0 & 0.298 & 0.401 & 0.364 & 0.166 & 0.296 \\
\cline { 2 - 7 } & 0.1 & 3.312 & 5.749 & 9.541 & 10.501 & 9.940 \\
\cline { 2 - 7 } & 0.01 & 4.592 & 5.852 & 7.813 & 8.789 & 9.515 \\
\hline
\end{tabular}

absorption of PMMA/ZnO nanocomposites and therefore enhances the UV resistance of such materials $[35,42,59,60]$. Transmittances at various UV wavelengths for $\mathrm{ZnO} / \mathrm{PMMA}$ nanocomposites are summarized in Table 3. UV absorption of $\mathrm{ZnO} /$ PMMA is very high in the wavelength region between 290 and $370 \mathrm{~nm}$ : $98 \%$ of the incident UV light is absorbed by 0.1 or $1 \%$ of nano $\mathrm{ZnO}$ in the composite (Table 4). Even at a very low concentration $(0.01 \%)$ of nano $\mathrm{ZnO}$, UV absorption is still between 60 and $90 \%$ of the incident UV light intensity, depending on the $\mathrm{ZnO}$ particle size.

Due to the application aspect we focused on the preparation of a PMMA nanocomposite with high UV opacity (absorption) and with optimal visible transparency, using the unmodified as-synthesized nano $\mathrm{ZnO}$ with the smallest particle sizes ( $\mathrm{ZnO}$ EG $32 \mathrm{~nm}$; ZnO PD $33 \mathrm{~nm}$ ) to reduce their optical scattering. Measured hydrodynamic radii (Table 2) show that even aggregates formed by $4-8 \mathrm{ZnO}$ particles

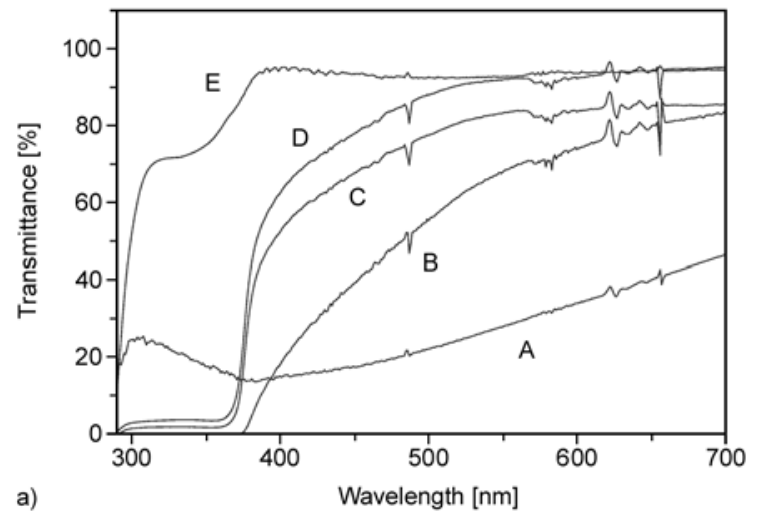

of these two $\mathrm{ZnO}$ samples have sizes close to $100 \mathrm{~nm}$ at $\mathrm{ZnO}$ concentration of $0.01 \mathrm{wt} \%$. For the preparation of larger PMMA sheets $(15 \times 20 \mathrm{~cm})$ we used the prepolymer procedure which is used industrially because it gives a product with excellent optical transparency [61]. Its purpose is to reduce the shrinking during the polymerization of MMA, thus preventing the formation of bubbles in the PMMA sheet. In order to additionally slow down the reagglomeration of $\mathrm{ZnO}$ particles after the sonication the concentration of nano $\mathrm{ZnO}$ was reduced to $0.05 \mathrm{wt} \%$. Surprisingly, UV absorption of these samples did not deteriorate, while their visible transparency was substantially enhanced (Figure $7 \mathrm{a}$ and $\mathrm{b}$ ). The influence of particle size on the UV-VIS absorption properties can be demonstrated by comparing the UV-VIS spectra of submicrometer $\mathrm{ZnO}$ (350 nm) composite (Figure $7 \mathrm{a} A$ and Figure $7 \mathrm{~b} \mathrm{~A}$ ) with those of nano $\mathrm{ZnO}$ (32 or $33 \mathrm{~nm}$ ) composite (Figure 7a B and Figure $7 \mathrm{~b} \mathrm{~B}$ ). Submicrometer $\mathrm{ZnO}$ composite

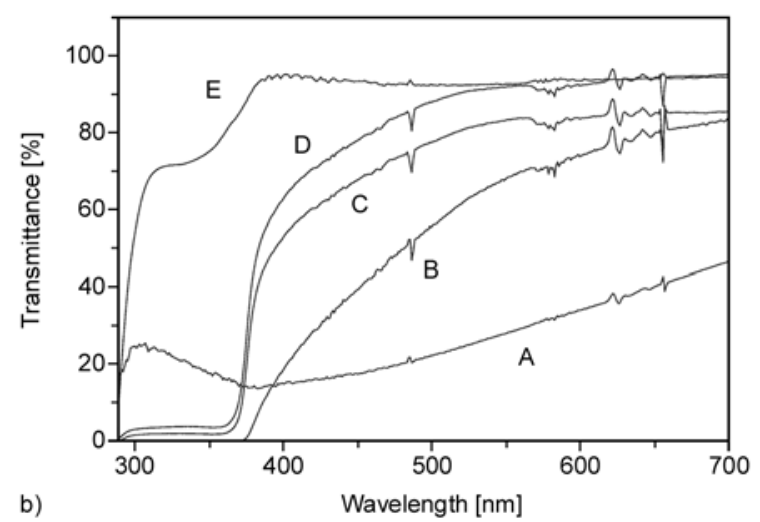

Figure 7. UV-VIS spectra of PMMA/ZnO nanocomposites in dependence of $\mathrm{ZnO}$ concentration and nanocomposite preparation procedure: a) $\mathrm{ZnO}$ synthesized in $\mathrm{EG} \mathrm{A}$ ) submicrometer (350 nm) $\mathrm{ZnO} 0.1 \%$ - procedure $\mathrm{B}$, B) $0.1 \%$ procedure $\mathrm{B}, \mathrm{C}$ ) $0.05 \%$ - procedure $\mathrm{B}$, D) $0.05 \%$ - procedure $\mathrm{C}$, E) pure PMMA; b) ZnO synthesized in PD A) submicrometer $(350 \mathrm{~nm}) \mathrm{ZnO} 0.1 \%$ - procedure $\mathrm{B}, \mathrm{B}) 0.1 \%$ - procedure $\mathrm{B}$, C) $0.05 \%$ - procedure $\mathrm{B}$, D) $0.05 \%$ - procedure C, E) pure PMMA 
shows reduced absorption in the UV region and poor transparency for visible light compared to the nano $\mathrm{ZnO}$ composite.

TEM micrographs of PMMA/ZnO nanocomposites prepared by the prepolymer procedure show homogeneously distributed $\mathrm{ZnO}$ particles with particle sizes up to $100 \mathrm{~nm}$ and only a few agglomerates with sizes between 100 and $300 \mathrm{~nm}$ (Figure 8). Rather low number of particles in TEM micrographs (Figure $8 \mathrm{a}$ and $\mathrm{b}$ ) may cause doubts about the high UV absorption of these nanocomposites. The particles in Figure 8b were counted and there were 106 particles or agglomerates in a $100 \mathrm{~nm}$ thick section. Considering that the thickness of nanocomposite plate is $3.5 \mathrm{~mm}$, and assuming that nano $\mathrm{ZnO}$ is uniformly distributed in PMMA matrix, this number should be multiplied with $3.5 \cdot 10^{4}$ to get the number of particles through the entire cross-section of the plate, giving the final particle number of $3.7 \cdot 10^{6}$. This is a very large number and therefore the probability that a photon of UV light hits or interacts with a $\mathrm{ZnO}$ particle is very high, explaining thus the very high UV absorption at rather low concentrations of nano $\mathrm{ZnO}$.

The aggregation of nano $\mathrm{ZnO}$ particles was additionally reduced using sonication through the entire prepolymer synthesis (Procedure C). Sonication is very effective in breaking up the $\mathrm{ZnO}$ aggregates. After the sonication is stopped, $\mathrm{ZnO}$ particles can not reagglomerate again due to entrapment in PMMA chains. UV-VIS spectra of these samples (Figures $7 \mathrm{a} D$ and Figures $7 \mathrm{~b}$ D) confirm that these materials are optically transparent with slightly yellowish color as a consequence of some optical scat-

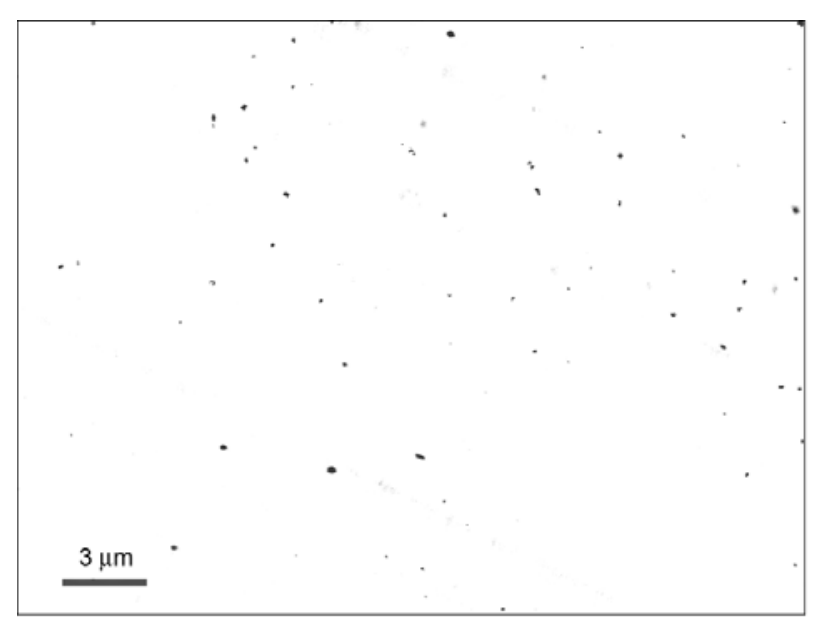

a) tering due to the presence of small amounts of larger agglomerates. Such materials have potential application as UV opaque or UV stabilized transparent PMMA sheets.

PMMA materials are often used in various outdoor applications in which they are exposed to high loads of sunlight. In such conditions the colorless transparent materials change their color to yellow or brown, and even their mechanical properties are deteriorated. We tested the resistance of the nanocomposites to sunlight by the Sun test (Table 5). Differences in $\triangle \mathrm{E}$ values indicate a significant enhancement of $\mathrm{ZnO} / \mathrm{PMMA}$ resistance to sunlight compared to pure PMMA. The color change (yellowing) is a consequence of the photodegradation of PMMA chains. There are two possible mechamisms which contribute to the reduction of yellowing in PMMA/ $\mathrm{ZnO}$ nanocomposites. The first one is the high UV absorption of nano $\mathrm{ZnO}$ causing less UV light to penetrate into the material and causing degradation of PMMA. The second one is that nano $\mathrm{ZnO}$ causes changes in the chemical structure of PMMA (lower concentration of vinylidene chain end double bonds),

Table 5. Resistance to sunlight (Sun test) in dependence of nano $\mathrm{ZnO}$ concentration: $\mathrm{ZnO}(\mathrm{EG}-32 \mathrm{~nm}$ and $\mathrm{PD}-33 \mathrm{~nm})$

\begin{tabular}{|l|c|c|}
\hline \multicolumn{1}{|c|}{ Sample designation } & $\begin{array}{c}\mathbf{Z n O} \\
{[\mathbf{w t} \%]}\end{array}$ & $\Delta \mathbf{E}^{\mathbf{a}}$ \\
\hline $\mathrm{PMMA}$ & 0 & $10.6-10.8$ \\
\hline $\mathrm{ZnO}(\mathrm{PD}) / \mathrm{PMMA}$ & 0.05 & $3.1-4.6$ \\
\hline $\mathrm{ZnO}(\mathrm{PD}) / \mathrm{PMMA}$ & 0.1 & $0.6-0.9$ \\
\hline $\mathrm{ZnO}(\mathrm{EG}) / \mathrm{PMMA}$ & 0.05 & $4.1-4.3$ \\
\hline $\mathrm{ZnO}(\mathrm{EG}) / \mathrm{PMMA}$ & 0.1 & $1.7-2.1$ \\
\hline
\end{tabular}

${ }^{\mathrm{a}} \Delta E$ is colour change measured by colorimeter relatively to the unexposed sample

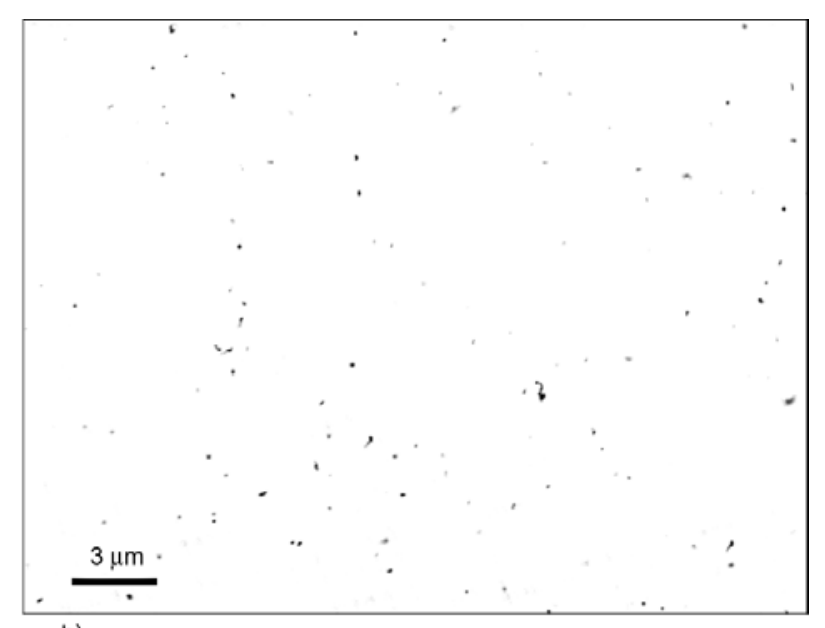

b)

Figure 8. TEM micrographs of PMMA/ZnO nanocomposite prepared by the prepolymer procedure (procedure $\mathrm{B})(\mathrm{ZnO}$ concentration $=0.1 \%)$ : a) $\mathrm{ZnO}(\mathrm{PD}-33 \mathrm{~nm})$, b) $\mathrm{ZnO}(\mathrm{EG}-32 \mathrm{~nm})$ 

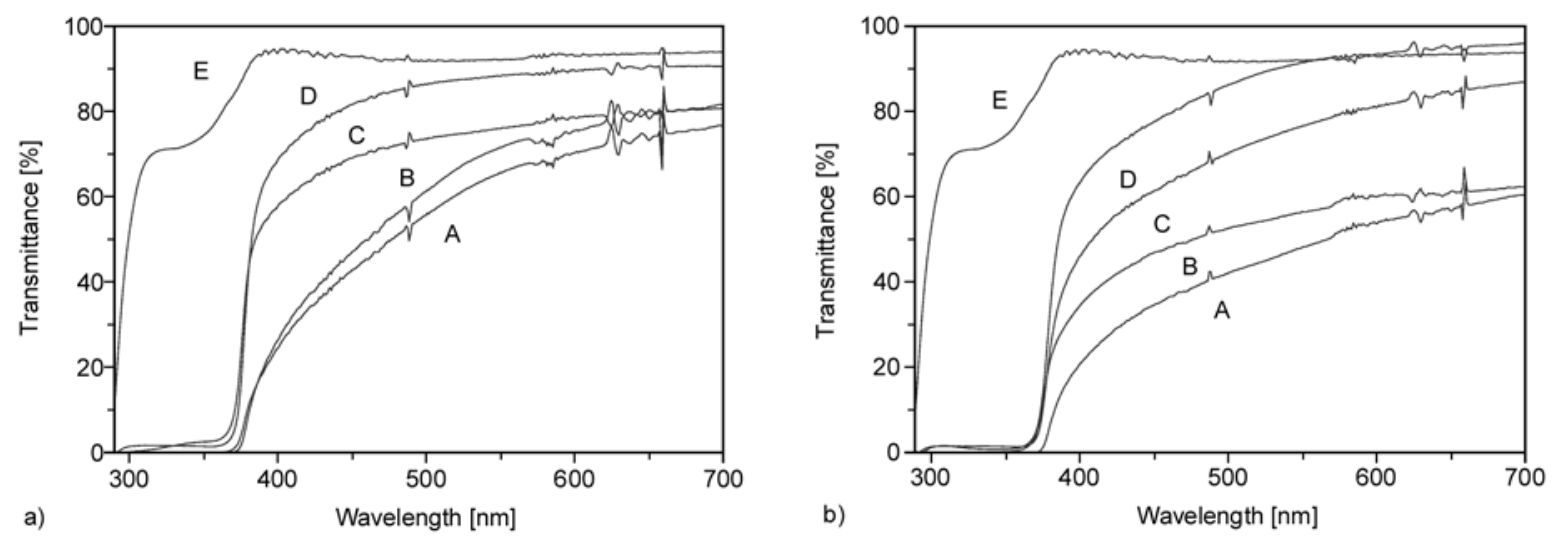

Figure 9. UV-VIS spectra of $\mathrm{ZnO} / \mathrm{PMMAnanocomposites} \mathrm{exposed} \mathrm{to} \mathrm{sun} \mathrm{test} \mathrm{compared} \mathrm{to} \mathrm{unexposed} \mathrm{samples} \mathrm{in} \mathrm{depend-}$ ence of $\mathrm{ZnO}$ concentration: a) $\mathrm{ZnO}(\mathrm{EG}-32 \mathrm{~nm})$, b) $\mathrm{ZnO}$ (PD - $33 \mathrm{~nm}$ ): A) $0.1 \mathrm{wt} \% \mathrm{ZnO}$ unexposed sample, B) $0.1 \mathrm{wt} \% \mathrm{ZnO}$, C) $0.05 \mathrm{wt} \% \mathrm{ZnO}$ unexposed sample, D) $0.05 . \% \mathrm{ZnO}$, E) pure PMMA

if MMA is polymerized in its presence [30, 33]. Vinylidene double bonds are weak points where the photodegradation of PMMA starts and their lower concentration in PMMA chains means that such material is more resistant to photodegradation.

UV-VIS spectra of PMMA/ZnO nanocomposites exposed to the sun test show a small decrease in visible transparency due to color change during the sun test (Figure 9). It can be also seen that $\mathrm{ZnO}$ particles synthesized in PD (Figure 9b) showed higher protection to sunlight than those synthesized in EG (Figure 9a) and that protection is more effective at higher $\mathrm{ZnO}$ concentration $(0.1 \mathrm{wt} \%)$, as expected. These results indicate the high potential of these materials in applications with high exposure to sunlight.

Preparation of $\mathrm{ZnO} / \mathrm{PMMA}$ nanocomposites has attracted considerable attention in the last seven years. Most authors studied the preparation of $\mathrm{ZnO} / \mathrm{PMMA}$ nanocomposites in the form of thin films from the solution $[36,54,58-60,62]$. In our case we used unmodified $\mathrm{ZnO}$ for the preparation of nanocomposites. Synthesized $\mathrm{ZnO}$ is organophilic due to the presence of organometallic intermediates and solvent (diol) residues on the particle surface. The synthetic procedure of $\mathrm{ZnO}$ filler preparation is quite simple and also easy to transfer to a pilot level. We used an industrially used prepolymer procedure for the preparation of $3.5 \mathrm{~mm}$ thick nanocomposite plates. Due to the absence of additional surface modification the highest nano $\mathrm{ZnO}$ concentration to obtain transparent materials is rather low $(0.05-0.1 \mathrm{wt} \%)$ but we showed that even in this concentration range UV absorption (above 95\%) and protection from sunlight are very high. The absence of surfactants is an advantage because they can change other properties of these materials (e.g. mechanical properties, sunlight stability), making them unsuitable for outdoor applications. UV absorption and sunlight resistance as well as thermal stability are additionally improved at nano $\mathrm{ZnO}$ concentrations higher than $0.1 \mathrm{wt} \%$ where visible transparency becomes rather poor. Such nanocomposites can be applied for various nontransparent PMMA materials such as aluminium hydroxide filled PMMA or other highly filled PMMA materials.

\section{Conclusions}

Nano ZnO particles have been synthesized by the polyol method in various diols (EG, PD, BD and TEG) with and without $\mathrm{p}-\mathrm{TsOH}$ as an end capping agent. The addition of $\mathrm{p}-\mathrm{TsOH}$ reduces the average particle size and increases the $\mathrm{ZnO}$ crystallinity as compared to $\mathrm{ZnO}$ prepared without $\mathrm{p}-\mathrm{TsOH}$. Particle sizes of nano $\mathrm{ZnO}$ particles, prepared in various diols, are in correlation with the diol chain length. With increased diol chain length the average particle size of $\mathrm{ZnO}$ is also increased (EG $32 \mathrm{~nm}, \mathrm{PD}$ $33 \mathrm{~nm}$, BD $72 \mathrm{~nm}$, TEG $86 \mathrm{~nm}$ ). Zn(II) acetate hydrolysis in diols proceeds through the $\mathrm{Zn}_{4} \mathrm{O}\left(\mathrm{CH}_{3} \mathrm{COO}\right)_{6}$ reaction intermediate as supported by FTIR and ${ }^{13} \mathrm{C}$ NMR spectroscopy.

Unmodified as-synthesized nano $\mathrm{ZnO}$ powders were used for the preparation of PMMA nanocomposites. Dispersions of $\mathrm{ZnO}$ particles in the monomer, MMA, in the concentration range between 0.01 and $0.1 \mathrm{wt} \%$ are stable for at least $45 \mathrm{~min}$, although they form agglomerates consisting of two to six parti- 
cles. TEM micrographs of nanocomposites also show small agglomerates of $\mathrm{ZnO}$ nanoparticles homogeneously distributed in the PMMA matrix, thus confirming the results of DLS measurements. $\mathrm{ZnO}$ nanoparticles thermally stabilize the PMMA matrix by shifting its $5 \%$ weight loss degradation temperature from 10 to $30{ }^{\circ} \mathrm{C}$ towards higher temperatures in dependence on the particle size. $\mathrm{ZnO}$ with smaller average particle sizes show a more intense stabilization effect. Thermal stabilization of nanocomposites is dependent on the $\mathrm{ZnO}$ concentration: the addition of $1 \mathrm{wt} \%$ of $\mathrm{ZnO}$ shifts $5 \%$ weight loss degradation temperature by $30^{\circ} \mathrm{C}$ to higher temperatures, while at lower $\mathrm{ZnO}$ concentrations shifts are rather small.

$\mathrm{ZnO} / \mathrm{PMMA}$ nanocomposites exhibit excellent absorption of UV light in the region between 290 and $370 \mathrm{~nm}$ even at concentrations of only $0.05 \mathrm{wt} \%$ of nano $\mathrm{ZnO}$. The transmittance of the visible light was optimized by reducing the $\mathrm{ZnO}$ concentration and by modifying the nanocomposite preparation procedure. Nanocomposites with efficient UV absorption and high visible light transmittance were prepared by the prepolymer procedure using constant sonication during the prepolymer synthesis at $\mathrm{ZnO}$ concentrations between 0.05 and $0.1 \mathrm{wt} \%$. Nano $\mathrm{ZnO}$ significantly enhances the resistance to sunlight depending on the concentration of $\mathrm{ZnO}$, thus giving these materials high potential in various applications with high UV and sunlight loads.

\section{Acknowledgements}

The financial support of Slovenian Ministry of Higher Education, Science and Technology, Slovenian Research Agency and EU Research Agency through research programmes P2-0145, P2-030 and Novapol ERA-NET MNT project is gratefully acknowledged. The authors thank Andrej Beličič, M.Sc., of the Kolpa company for the Sun test measurements and Igor Djerdj, Ph.D., of the Rudjer Boskovic institute for HR TEM microscopy.

\section{References}

[1] Xie W., Yang Z., Chun H.: Catalytic properties of lithium-doped $\mathrm{ZnO}$ catalysts used for biodiesel preparations. Industrial and Engineering Chemistry Research, 46, 7942-7949 (2007).

DOI: $10.1021 / \mathrm{ie} 070597 \mathrm{~s}$

[2] Hoffman A. J., Yee H., Mills G., Hoffmann M. R.: Photoinitiated polymerization of methyl methacrylate using Q-sized ZnO colloids. Journal of Physical Chemistry, 23, 5540-5546 (1992).

DOI: $\underline{10.1002 / \text { chin. } 199240085}$
[3] Rout C. S., Raju A. R., Govindaraj A., Rao C. N. R.: Ethanol and hydrogen sensors based on $\mathrm{ZnO}$ nanoparticles and nanowires. Journal of Nanoscience and Nanotechnology, 7, 1923-1929 (2007).

DOI: $10.1166 / \mathrm{jnn} .2007 .742$

[4] Rout C. S., Hedge M., Govindaraj A., Rao C. N. R.: Ammonia sensors based on metal oxide nanostructures. Nanotechnology, 18, 205504/1-205504/9 (2007). DOI: $10.1088 / 0957-4484 / 18 / 20 / 205504$

[5] Ayudhya S. K. N., Tonto P., Mekasuwandumrog O., Pavarajarn V., Praserthdam P.: Solvothermal synthesis of $\mathrm{ZnO}$ with various aspect ratios using organic solvents. Crystal Growth and Design, 6, 2446-2450 (2006).

DOI: $10.1021 / \operatorname{cg} 050345 \mathrm{z}$

[6] Zhang J., Sun L., Yin J., Su H., Liao C., Yan C.: Control of $\mathrm{ZnO}$ morphology via a simple solution route. Chemistry of Materials, 14, 4172-4177 (2002). DOI: $10.1021 / \mathrm{cm} 020077 \mathrm{~h}$

[7] Peiró A. M., Ravirajan P., Govender K., Boyle D. S., O’Brien P., Bradley D. D. C., Nelson J., Durrant J. R.: Hybrid polymer/metal oxide solar cells based on $\mathrm{ZnO}$ columnar structures. Journal of Materials Chemistry, 16, 2088-2096 (2006).

DOI: $10.1039 / \mathrm{b} 602084 \mathrm{~d}$

[8] Lin C-C., Lee W-S., Sun C-C., Whu W-H.: A varistorpolymer composite with nonlinear electrical-thermal switching properties. Ceramics International, 34, 131136 (2008).

DOI: $10.1016 /$ j.ceramint.2006.09.018

[9] Pal U., Serrano J. G., Santiago P., Xiong G., Ucer K. B., Williams R. T.: Synthesis and optical properties of $\mathrm{ZnO}$ nanostructures with different morphologies. Optical Materials, 29, 65-69 (2006).

DOI: $10.1016 /$ j.optmat.2006.03.015

[10] Liu D-P., Li G-D., Su Y., Chen J-S.: Highly luminescent $\mathrm{ZnO}$ nanocrystals stabilized by ionic-liquid components. Angewandte Chemie, International Edition, 45, 7370-7373 (2006).

DOI: $10.1002 /$ anie. 200602429

[11] Schwartz D. A., Norberg N. S., Nguyen Q. P., Parker J. M., Gamelin D. R.: Magnetic quantum dots: Synthesis, spectroscopy, and magnetism of $\mathrm{CO}^{2+}$ - and $\mathrm{Ni}^{2+}$-doped $\mathrm{ZnO}$ nanocrystals. Journal of the American Chemical Society, 125, 13205-13218 (2003). DOI: $10.1021 / \mathrm{ja} 036811 \mathrm{v}$

[12] Hu Y., Jiang Z., Xu C., Mei T., Guo J., White T.: Monodisperse $\mathrm{ZnO}$ nanodots: Synthesis, charaterization, and optoelectronic properties. Journal of Physical Chemistry, 111, 9757-9760, (2007).

DOI: $10.1021 /$ jp0726384

[13] Ghoshal T., Kar S., Chaudhuri S.: ZnO doughnuts: Controlled synthesis, growth mechanism, and optical properties. Crystal Growth and Design, 7, 136-141 (2007).

DOI: $10.1021 / \operatorname{cg} 060289 \mathrm{~h}$ 
[14] Demir M. M., Muñoz-Espí R., Lieberwirth I., Wegner G.: Precipitation of monodisperse $\mathrm{ZnO}$ nanocrystals via acid-catalyzed esterification of zinc acetate. Journal of Materials Chemistry, 16, 2940-2947 (2006).

DOI: $10.1039 / \mathrm{b} 601451 \mathrm{~h}$

[15] Bitenc M., Dražić G., Orel Z. C.: Characterization of crystalline zinc oxide in the form of hexagonal bipods. Crystal Growth and Design, 10, 830-837 (2010). DOI: $10.1021 / \mathrm{cg} 901193 \mathrm{~g}$

[16] Ambrožič G., Djerdj I., Škapin S. D., Žigon M., Orel Z. C.: The double role of p-toluenesulfonic acid in the formation of $\mathrm{ZnO}$ particles with different morphologies. CrystEngComm, 12, 1862-1868 (2010). DOI: $10.1039 / \mathrm{b} 924412 \mathrm{n}$

[17] Liu B., Zeng H. C.: Hydrothermal synthesis of $\mathrm{ZnO}$ nanorods in the diameter regime of $50 \mathrm{~nm}$. Journal of the American Chemical Society, 125, 4430-4431 (2003).

DOI: $10.1021 /$ ja0299452

[18] Sun X. M., Chen X., Deng Z. X., Li Y. D.: A CTABassisted hydrothermal orientation growth of $\mathrm{ZnO}$ nanorods. Materials Chemistry and Physics, 78, 99104 (2003). DOI: 10.1016/S0254-0584(02)00310-3

[19] Bitenc M., Podbršček P., Orel Z. C., Cleveland M. A., Paramo J. A., Peters R. M., Strzhemecny Y. M.: Correlation between morphology and defect luminescence in precipitated $\mathrm{ZnO}$ nanorod powders. Crystal Growth and Design, 9, 997-1001 (2009).

DOI: $10.1021 / \operatorname{cg} 8008078$

[20] Yang L., Wang G. Z., Tang C. J., Wang H. Q., Zhang L.: Synthesis and photoluminescence of corn-like $\mathrm{ZnO}$ nanostructures under solvothermal-assisted heat treatment. Chemical Physics Letters, 409, 337-341 (2005). DOI: 10.1016/j.cplett.2005.05.015

[21] Yu S-H., Yang J., Quian Y-T., Yoshimura M.: Optical properties of $\mathrm{ZnS}$ nanosheets, $\mathrm{ZnO}$ dendrites, and their lamellar precursor $3 \mathrm{ZnS} \cdot\left(\mathrm{NH}_{2} \mathrm{CH}_{2} \mathrm{CH}_{2} \mathrm{NH}_{2}\right)_{0.5}$. Chemical Physics Letters, 361, 362-366 (2002).

[22] Ambrožič G., Škapin S. D., Žigon M., Orel Z. C.: The synthesis of zinc oxide nanoparticles from zinc acetylacetonate hydrate and 1-butanol or isobutanol. Journal of Colloid and Interface Science, 346, 317-323 (2010).

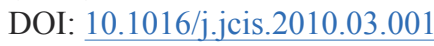

[23] Guo L., Ji Y., Xu H.: Regularly shaped, single-crystalline $\mathrm{ZnO}$ nanorods with wurtzite structure. Journal of the American Chemical Society, 124, 14864-14865 (2002).

DOI: $10.1021 / \mathrm{ja} 027947 \mathrm{~g}$

[24] Mondelaers D., Vanhoyland G., Van den Rul H., D’Haen J., Van Bael M. K., Mullens J., Van Poucke L. C.: Synthesis of $\mathrm{ZnO}$ nanopowder via an aqueous acetate-citrate gelation method. Materials Research Bulletin, 37, 901-914 (2002).

DOI: $10.1016 / \mathrm{S} 0025-5408(02) 00727-4$
[25] Wang Z., Zhang H., Zhang L., Yuan J., Yan S., Wang C.: Low-temperature synthesis of $\mathrm{ZnO}$ nanoparticles by solid-state pyrolytic reaction. Nanotechnology, 14, 11-15 (2003).

DOI: $10.1088 / 0957-4484 / 14 / 1 / 303$

[26] Pillai S. C., Kelly J. M., McCormack D. E., O’Brien P. O., Ramesh R.: The effect of processing conditions on varistors prepared from nanocrystalline $\mathrm{ZnO}$. Journal of Materials Chemistry, 13, 2586-2590 (2003). DOI: 10.1039/B306280E

[27] Masala O., Seshandri R.: Synthesis routes for large volumes of nanoparticles. Annual Review of Materials Research, 34, 41-81 (2004).

DOI: $10.1146 /$ annurev.matsci.34.052803.090949

[28] Feng X., Hu M. Z.: Ceramic nanoparticle synthesis. in 'Encyclopaedia of nanoscience and nanotechnology' (ed.: Nalwa H. S.) American Scientific Publishers, Stevenson Ranch, Vol 1, 687-726 (2004).

[29] Jézéquel D., Guenot J., Jouini N., Fiévet F.: Submicrometer zinc-oxide particles - Elaboration in polyol medium and morphological-characteristics. Journal of Materials Research, 1, 77-83 (1995).

DOI: $10.1557 / J M R .1995 .0077$

[30] Seelig E. W., Tang B., Yamilov A., Cao H., Chang R. P. H.: Self-assembled 3D photonic crystals from $\mathrm{ZnO}$ colloidal spheres. Materials Chemistry and Physics, 80, 257-263 (2003).

DOI: $10.1016 / \mathrm{S} 0254-0584(02) 00492-3$

[31] Anžlovar A., Crnjak Orel Z., Žigon M.: Morphology and particle size of di(ethylene glycol) mediated metallic copper nanoparticles. Journal of Nanoscience and Nanotechnology, 8, 3516-3525 (2008).

DOI: $10.1166 /$ jnn.2008.165

[32] Demir M. M., Memesa M., Castignolles P., Wegner G.: PMMA/zinc oxide nanocomposites prepared by in-situ bulk polymerization. Macromolecular Rapid Communications, 27, 763-770 (2006).

DOI: $10.1002 /$ marc. 200500870

[33] Muñoz-Espí R., Jeschke G., Lieberwirth I., Gómez C. M., Wegner G.: ZnO-latex hybrids obtained by polymer-controlled crystallization: A spectroscopic investigation. Journal of Physical Chemistry B, 111, 697707 (2007).

DOI: $10.1021 / j p 066380 \mathrm{~d}$

[34] Golovko D. S., Muñoz-Espí R., Wegner G.: Interaction between poly(styrene-acrylic acid) latex nanoparticles and zinc oxide surfaces. Langmuir, 23, 35663569 (2007). DOI: $10.1021 / 1 \mathrm{a} 0632880$

[35] Kickelbick G.: Concepts for the incorporation of inorganic building blocks into organic polymers on a nanoscale. Progress in Polymer Science, 28, 83-114 (2003). DOI: $10.1016 / \mathrm{S} 0079-6700(02) 00019-9$ 
[36] Khrenov V., Klapper M., Müllen K.: Surface functionalized $\mathrm{ZnO}$ particles designed for the use in transparent nanocomposites. Macromolecular Chemistry and Physics, 206, 95-101 (2005).

DOI: 10.1002/macp.200400213

[37] Khrenov V., Schwager F., Klapper M., Koch M., Müllen K.: Compatibilization of inorganic particles for polymeric nanocomposites. Optimization of the size and the compatibility of $\mathrm{ZnO}$ particles. Polymer Bulletin, 58, 799-807 (2007).

DOI: $10.1007 / \mathrm{s} 00289-006-0721-1$

[38] Hong R. Y., Quian J. Z., Cao J. X.: Synthesis and characterization of PMMA grafted $\mathrm{ZnO}$ nanoparticles. Powder Technology, 163, 160-168 (2006).

DOI: $10.1016 /$ j.powtec.2006.01.015

[39] Tang E. J., Cheung G. X., Ma X. L.: Preparation of nano-ZnO/PMMA composite particles via grafting of the copolymer onto the surface of zinc oxide nanoparticles. Powder Technology, 161, 209-214 (2006).

DOI: $10.1016 /$ j.powtec.2005.10.007

[40] Tang E. J., Chung G. X., Pang X. S., Ma X. L., Xing F. B.: Synthesis of nano-ZnO/poly(methyl methacrylate) composite microsphere through emulsion polymerization and its UV-shielding property. Colloid and Polymer Science, 284, 422-428 (2006).

DOI: $10.1007 / \mathrm{s} 00396-005-1389-\mathrm{Z}$

[41] Liu P., Su Z.: Preparation and characterization of PMMA/ZnO nanocomposites via in-situ polymerization method. Journal of Macromolecular Science: Physics, 45, 131-138 (2006). DOI: $10.1080 / 00222340500408085$

[42] Yu H. Y., Du J., Gu J. S., Guan M. Y., Wu Z. C., Ling Q., Sun Y. M.: Chemical modification on the surface of nano-particles of $\mathrm{ZnO}$ and its characterization (in Chinese). Spectroscopy and Spectral Analysis, 24, 177-179 (2004).

[43] Shim J-W., Kim J-W., Han S-H., Chang I-S., Kim HK., Kang H-H., Lee O-S., Suh K-D.: Zinc oxide/polymethylmethacrylate composite microspheres by in situ suspension polymerization and their morphological study. Colloids and Surfaces A: Physicochemical and Engineering Aspects, 207, 105-111 (2002). DOI: $10.1016 /$ S0927-7757(02)00044-4

[44] Tasbihi M., Lavrenčič Štangar U., Černigoj U., Kogej K.: Low-temperature synthesis and characterization of anatase $\mathrm{TiO}_{2}$ powders from inorganic precursors. Photochemical and Photobiological Sciences, 8, 719-725 (2009).

DOI: $10.1039 / \mathrm{b} 817472 \mathrm{e}$

[45] Heller R. B., McGannon J., Weber A. H.: Precision determination of the lattice constants of zinc oxide. Journal of Applied Physics, 21, 1283-1284 (1950). DOI: $10.1063 / 1.1699591$

[46] Sinha A., Sharma B. P.: Preparation of copper powder by glycerol process. Materials Research Bulletin, 37, 407-416 (2002).

DOI: $10.1016 / \mathrm{S} 0025-5408(01) 00819-4$
[47] Hayashi S., Nakamori N., Kanamori H.: Generalized theory of average dielectric constant and its application to infrared absorption by $\mathrm{ZnO}$ small particles. Journal of the Physical Society of Japan, 46, 176-183 (1979).

DOI: $10.1143 /$ JPSJ.46.176

[48] Johnson M. K., Powell D. B., Cannon R. D.: Vibrational-spectra of carboxylato complexes. 1. Infrared and Raman-spectra of berrylium(II) acetate and formate and of zinc(II) acetate and zinc(II) acetate dihydrate. Spectrochimica Acta, 37, 899-904 (1981). DOI: $10.1016 / 0584-8539(81) 80011-6$

[49] Johnson M. K., Powell D. B., Cannon R. D.: Vibrational spectra of carboxylato complexes-II. Some oxotetranuclear complexes. Spectrochimica Acta, 38, 125-131 (1982).

DOI: $10.1016 / 0584-8539(82) 80187-6$

[50] Berkesi O., Dreveni I., Körtvélyesi T., Andor J. A., Mink J., Goggin P. L.: Influence of the alkyl-chain on the symmetry and structural changes of $\mathrm{Zn}_{4} \mathrm{O}\left(\mathrm{RCO}_{2}\right)_{6}$ complexes in film phase - An FT-IR study. Vibrational Spectroscopy, 43, 227-236 (2007).

DOI: $10.1016 /$ j.vibspec.2006.08.002

[51] Schmidt T., Müller G., Spanhel L., Kerkel K., Forchel A.: Activation of $1.54 \mu \mathrm{m} \mathrm{Er}^{3+}$ fluorescence in concentrated II-VI semiconductor cluster environments. Chemistry of Materials, 10, 65-71 (1998).

DOI: $10.1021 / \mathrm{cm} 9702169$

[52] Dreveni I., Berkesi O., Janovics I., Andor J. A., Mink J.: Fourier transform infrared spectroscopic study on the molecular structure of bis(butanoato) zinc(II) and $\mu_{4}$-oxohexa- $\mu$-butanoatotetrazinc(II) complexes. Vibrational Spectroscopy, 2, 205-209 (1991).

DOI: 10.1016/0924-2031(91)85027-K

[53] Koshevar V. D.: The influence of poly(methyl methacrylate) on the stability of zinc oxide dispersions in nonaqueous media of various acidity. Colloid Journal of the Russian Academy of Sciences, 57, 649-652 (1995).

[54] Demir M. M., Castignolles P., Akbey Ü., Wegner G.: In-situ bulk polymerization of dilute particle/MMA dispersions. Macromolecules, 40, 4190-4198 (2007). DOI: $10.1021 / \mathrm{ma} 070142 \mathrm{e}$

[55] Ding Y., Gui Z., Zhu J., Wang Z., Hu Y., Song L.: Poly(methyl methacrylate)-nanoribbon nanocomposites with high thermal stability and improvement in the glass-transition temperature. Journal of Materials Research, 22, 3316-3323 (2007).

DOI: 10.1557/JMR.2007.0427

[56] Kashiwagi T., Inaba A., Brown J. E., Hatada K., Kitayama T., Masuda E.: Effects of weak linkages on the thermal and oxidative degradation of poly(methyl methacrylates). Macromolecules, 19, 2160-2168 (1986).

DOI: $10.1021 / \mathrm{ma} 00162 \mathrm{a} 010$ 
[57] Anžlovar A., Crnjak Orel Z., Žigon M.: Poly(methyl methacrylate) composites prepared by in situ polymerization using organophillic nano-to-submicrometer zinc oxide particles. European Polymer Journal, 46, 1216-1224 (2010).

DOI: $10.1016 /$ j.eurpolymj.2010.03.010

[58] Miyazaki H., Teranishi Y., Ota T.: Fabrication of UVopaque and visible-transparent composite film. Solar Energy Materials and Solar Cells, 90, 2640-2646 (2006).

DOI: 10.1016/j.solmat.2006.02.030

[59] Demir M. M., Koynov K., Akbey Ü., Bubeck C., Park I., Lieberwirth I., Wegner G.: Optical properties of composites of PMMA and surface-modified zincite nanoparticles. Macromolecules, 40, 1089-1100 (2007). DOI: $10.1021 / \mathrm{ma} 062184 \mathrm{t}$
[60] Sun D., Miyatake N., Sue H-J.: Transparent PMMA/ $\mathrm{ZnO}$ nanocomposite films based on colloidal $\mathrm{ZnO}$ quantum dots. Nanotechnology, 18, 215606/1-215606/6 (2007).

DOI: $10.1088 / 0957-4484 / 18 / 21 / 215606$

[61] Slone R. V.: Methacrylic polymers. in 'Kirk-Othmer encyclopedia of chemical technology' Wiley, New York, Vol 16, 271-298 (2005).

DOI: $10.1002 / 0471238961.1305200814152201 . a 01$. pub2

[62] Xiong M., Gu G., You B., Wu L.: Preparation and characterization of poly(styrene butylacrylate) latex/nano- $\mathrm{ZnO}$ nanocomposites. Journal of Applied Polymer Science, 90, 1923-1931 (2003).

DOI: $\underline{10.1002 / a p p .12869}$ 